(C) 2020. This manuscript version is made available under the CC-BY-NC-ND 4.0 license http:// creativecommons.org/licenses/by-nc-nd/4.0/

\title{
A Novel Hybrid Multi-Criteria Group Decision Making Approach for Failure Mode and Effect Analysis: An Essential Requirement for Sustainable Manufacturing
}

\author{
Soumava Boral ${ }^{1,2}$, Ian Howard ${ }^{2 *}$, Sanjay K. Chaturvedi ${ }^{1}$, Kristoffer McKee ${ }^{2}$, V.N.A. Naikan ${ }^{1}$, \\ ${ }^{1}$ Subir Chowdhury School of Quality and Reliability, Indian Institute of Technology Kharagpur, \\ Kharagpur, India - 721302 \\ ${ }^{2}$ School of Civil and Mechanical Engineering, Curtin University, WA - 6102 \\ [*Communicating author =I.Howard@exchange.curtin.edu.au $]$
}

\section{Abstract:}

Modern manufacturing organizations have started giving paramount importance to sustainable aspects of the manufacturing processes, realising not only that the natural resources are dwindling rapidly but also that they bear significant responsibility to the society and surroundings for the overall future development. Catastrophic failures and the maintenance of complex equipment can generate a large amount of hazardous waste within the organization that can affect the overall production level, environment, along with impacting the health of workers in the long run. Failure mode and effect analysis (FMEA) is an efficient risk analysis tool for processes, products, designs or services and has been adopted by different types of organizations. In this paper, for the first time in the literature, the consequences of failure modes of industrial equipment are considered from the sustainable point of view, which is believed to be a requirement for the establishment of a successful sustainable manufacturing strategy. Severity of failure modes are considered from environmental, societal and economic points of view, along with the chances of occurrence and detection. However, due to lack of exact data, these risk factors are evaluated linguistically by cross-functional experts, which made the situation complex. To properly prioritize the failure modes according to their risk levels, a novel hybrid Multi-Criteria Group Decision Making (MCGDM) approach by integrating Interval Type-2 Fuzzy Decision-Making Trial and Evaluation Laboratory (IT2F-DEMATEL) and Modified Fuzzy MultiAttribute Ideal Real Comparative Analysis (Modified FMAIRCA) methods is proposed. Calculating the causal dependencies among the risk factors and finding out their relative importance are the twofold benefits of the IT2F-DEMATEL approach. Defuzzified criteria weights are further utilized in the proposed modified FMAIRCA approach for risk ranking of failure modes. The effectiveness of the proposed hybrid approach is demonstrated by considering a case-study from a process plant gearbox. Next, the obtained ranking results are compared with the results obtained from other commonly applied fuzzy MCDM methods in the FMEA domain. Stability and robustness of the proposed approach is also highlighted by performing sensitivity analysis.

Index Terms: Failure mode and effect analysis; Sustainable manufacturing; Interval type-2 fuzzy sets; DEMATEL; Fuzzy MAIRCA; Process plant gearbox. 


\section{Introduction}

A hazard is described as anything that can cause harm to the society, such as injury, death, damage to environment, reputation, property, and economic balance of an organization. Risk is defined as the possibility that harm may occur due to exposure to the hazard. Most organizations try to identify the causes of hazards, estimate their risks, take appropriate proactive measures to eliminate/mitigate/control them and then monitor the control measures regularly. However, risk estimation related to any process, product, service or design is known to be a tedious task due to the involvement of multiple indices which are hard to articulate. As per IEC 31010: 2019, there are several types of risk assessment techniques that include interviews, Delphi, HAZOP (Hazard and Operability Analysis), RCA (Root Cause Analysis), FMEA (Failure Mode and Effect Analysis), FTA (Fault tree analysis), ETA (Event Tree Analysis), etc.

Failure mode and effect analysis (FMEA) has been considered as a proactive risk management tool in reliability engineering where systems, processes, designs or services are evaluated systematically to find out their different potential failure modes, problems, errors and subsequent effects on the system level. Subsequently, feasible alternatives are recommended and adopted to eliminate/mitigate the consequences due to those failures modes [1]. From the historical perspective, this tool was first developed as a formal design methodology in the 1960s for meeting the safety and reliability requirements of the aerospace industry [2]. Later, it was adopted by different types of industrial sectors, such as the automotive [3]-[5], nuclear [6], manufacturing [7]-[10], etc. for its simplicity and ease of application. As a whole, a complete FMEA analysis of a system spans from the bottom to the top level in a system hierarchy, where the known potential failure modes are identified by the FMEA team members at the lower level, the effects of which are progressively investigated at the next or higher level of the system hierarchy [1].

In the traditional FMEA approach, associated risks of failure modes are generally expressed by developing risk priority numbers (RPNs) obtained through the multiplication of three risk factors (RFs), viz., severity (S), probability of occurrence (O) and probability of detection (D). These RFs are evaluated by cross-functional experts according to a particular scale having scale values between 1 to 10, where 10 implies the most severe fault, having the most frequent occurrence, with the least detectable failure mode and 1 implies the reverse (i.e., least severe, least frequent, and highly detectable failure mode). However, this traditional FMEA approach has been criticized due to the following main reasons [1], [11]:

- RFS are evaluated and rated with respect to different failure modes by the cross-functional experts (team members) using some linguistic terms, like - high, very high, low, etc. Later these linguistic evaluations are converted to a customized crisp scale (usually between 110), omitting the existing and inherent vagueness. 
- Total combinations of say 1000 RPNs contain numerical values which are not unique and are repeated several times. Histogram plots of these RPNs show that they are heavily concentrated at the bottom of the scale. This multiplicity of RPN values may not reveal hidden risk implications of each FM.

- Small variations in ratings of RFs may change the overall risk-ranking of the failure modes.

- Multiplicative operation is performed to obtain the final RPN value, which is debatable as it lacks a strong mathematical foundation.

- It does not consider the relative importance of each RF during the calculations of RPN.

- Each RF (i.e., severity) is implicitly defined. But, in actual case it is case-specific.

The idea of sustainability and sustainable development was first propounded after the 1987's Brundtland Report (World Commission of Environment and Development) by the UN. It defines the sustainable development as "...development that meets the needs of the present without compromising the ability of future generations to meet their own needs". The U.S. Department of Commerce defined sustainable manufacturing as "...the creation of manufactured products that use processes that minimize negative environmental impacts, conserve energy and natural resources, are safe for employees, communities, and consumers and are economically sound " [12]. Moreover, from the last two decades, it is evident that manufacturing industries are heavily pushed to consider sustainability aspects as a major point of concern to save the planet. The Governments have started formulating and enforcing the statutory regulations (e.g., Clean Air Act (1970), Resource Conservation and Recovery Act (1976) and Toxic Substance Control Act (1976)), which are mainly based on the environmental impacts of hazardous waste produced by systems/machinery during their operational, maintenance phases or after their failure [13]. Apart from these regulations, there are several other standards like ISO 45001 (related to health and safety), ISO 37001 (anti-bribery management systems), ISO 14064 (greenhouse gases), and TS 14067 (carbon footprint of products) that have also broadened the concept of sustainable development to now include economic, social and environmental aspects [14].

Generally, different types of hazardous waste (e.g., burnt oil, grease, hazardous gases) are produced due to the failure of large scale and complex machines, which have a significant impact on the working surroundings. Apart from that, when a machine operates in a degraded condition, excess energy is consumed, and sometimes toxic substances are generated that adversely affect the environment [13]. From an economical point of view, a considerable amount of the budget is utilized to repair and maintain these machines. Furthermore, in degraded condition, poor quality products are produced by these machines, which are either reused or discarded, leaving a large amount of scrap, causing further significant economic and ecological damage. Socially, the chances of occurrence of fatal accidents are increased when failures of critical machines occur as it can affect the workers' mind-set, besides causing delays and frustration in completing other assigned tasks. 
It is obvious from the preceding discussion that to make the FMEA approach suitable for sustainable manufacturing practices and industrial need, it is necessary to consider the severities of failure modes from multiple aspects, like economical severity, social severity and environmental severity. These subfactors are further decoupled into multiple sub-sub factors for more accurate risk-ranking of failure modes. This type of problem is considered as a multi-criteria decision making (MCDM) problem: based on multiple conflicting RFs, the failures modes are ranked based on their criticality. However, in such problems, RFs are rated linguistically by cross-functional experts due to the unavailability of exact information, the fluctuating nature of information and variability in judgement, etc. The Type-1 fuzzy set (T1 FS), proposed by Zadeh [15] is an efficient approach to deal with such natural languages and to provide optimal decisions. It is often combined with MCDM approaches to make more rational decisions. A detailed review of the applications of MCDM approaches, combined with T1 FS for solving FMEA problems is presented in [16]. Subsequently, the concept of type-2 fuzzy set (T2 FS), as an extension of T1 FS was propounded by Zadeh [17]. The main difference between these two types of FSs is that the membership grade of T1 FS is a real number in [0,1], whereas in T2 FS it is a fuzzy number with a support bounded by the interval $[0,1]$. Further, the membership function in T2 FS includes a footprint of uncertainty (FOU) that provides additional degrees of freedom for directly modelling and for handling of uncertainties. In fact, T2 FSs were introduced to capture the fuzziness of the membership function. However, considering the computational complexity of T2 FS, it has only had limited application for real world applications. Interval type-2 fuzzy sets (IT2FSs) are mostly used instead of T2 FS due to their ease of application, less computational effort, more flexibility, and being able to handle the linguistic uncertainties since they can be described by primary and secondary membership. However, it is admitted that both hard and soft computational complexity of IT2FS is higher than that of T1 FS, and hence to keep a balance between computational complexity and acceptable accuracy in the decision making problem, both T1 FS and IT2FS are employed in this paper.

A hybrid MCGDM framework is presented in this paper, by combining IT2F-DEMATEL and modified FMAIRCA approaches. The reasons for using IT2F-DEMATEL are twofold: to derive the causal relationships among the RFs, as well as to derive their relative importance. From the causal diagram, it is easy to identify those RFs which have strong influence on others [18]. The relative importance of the RFs is later utilized in our modified FMAIRCA approach for risk-ranking of failure modes. The MAIRCA approach was first developed by Pamučar et al. [19]. The basic idea of this method is to determine the gap between ideal and empirical ponders. The gap for each criteria of the alternatives are summed up and ranked accordingly thereafter. The best alternative always has the lowest gap value, while the worst has the highest gap value. Following are the major advantages of this MCDM method:

- Decision makers are unbiased in selecting any alternative. Hence, there is equal probability in selecting the best alternative [20]. 
- This method has simple mathematical calculations, solution stability and is easy to combine with other methods [20]-[22].

- This approach has proven to be more stable than other popular methods, like the Technique for Order Preference by Similarity to Ideal Solution (TOPSIS) and ELimination Et Choix Traduisant la REalité (ELECTRE) [23].

From the preceding discussions, and three review works [16], [24], [25], the following points are observed, which are aimed to be presented in this paper:

- Severity of a failure mode is decoupled into economical, societal and ecological severity. This approach is believed to be helpful in sustainable manufacturing practice within an organization. To illustrate the idea in a well-organized manner, a novel case-study of a process plant gearbox is considered. In that case-study, different components of a gearbox are presented along with their failure modes, causes and effects.

- After observing the effectiveness of IT2FS, TI FS, DEMATEL, and MAIRCA, a hybrid MCGDM approach is developed by combining IT2F-DEMATEL and modified FMAIRCA. The detailed analysis of RFs is carried out after getting outputs from the IT2F-DEMATEL approach. The modifications in the FMAIRCA method are carried out to improve the traditional method.

The rest of the paper is organized as follows: In Section 2, a literature review related to decoupling of RFs in FMEA problems and recent applications of different MCDM approaches for solving FMEA problems are presented. In Section 3, preliminaries of fuzzy numbers, IT2FS, IT2F numbers, and their arithmetic operations are briefly explained. In Section 4, the hybrid approach is presented and in Section 5 a case-study is supplemented to highlight the effectiveness of the proposed approach. Section 6 presents the validation of the proposed hybrid approach. Finally, in Section 7, the conclusion is given.

\section{Literature review}

\subsection{Decoupling risk factors in FMEA}

To make the FMEA approach more pertinent to the industrial needs, several researchers have considered additional risk factors apart from the traditional ones commonly in use. Garrick [26] considered multiple indices like quality loss of the product, environmental safety, production loss, and 'domino effects' for estimating risks associated with different industries. In [27], the author considered FMECA as an MCDM problem, and considered four different factors, viz., chance of failure, chance of non-detection, severity and expected cost for risk estimation. Finally, failure modes were ranked according to their risk levels by using the Analytic Hierarchy Process (AHP). Rhee \& Ishii [28] proposed a concept of life cost based FMEA, wherein risk was considered from the economical point of view. In [29], severity was detailed into safety, quality, maintenance cost and mean time to repair, considering the overall 
customer's satisfaction. Von Ahsen [30] and Carmiganani [31] also solved FMEA problems from the economical point of view. In [32] severity was decoupled into damage caused to safety, environment, production costs and maintenance costs. Further, detectability was categorized into sub-levels, such as detailed inspections, generic inspections, switchboard detection and detection by the naked eye. Silvestri et al. [33] proposed the concept of safety improved risk assessment by combining the concept of conventional FMEA with economic considerations. In their work, Das Adhikary et al. [34] considered multiple factors such as human attributes (operator's skill, maintenance personnel skill), factors related to the operating environment, downtime reduction factors (maintainability, spare parts availability) and economic factors (economic loss of a failure) while performing FMEA in a thermal power plant. Recently, Yousefi et al. [35] in their work considered HSE (health, safety and environment) for risk prioritization, considering two additional factors, namely, cost and duration of treatment of workers along with traditional severity, occurrence and detection.

From this above review, it is observed that none of the previous researchers have aimed to consider the severity from the triple bottom line (TBL) aspect of sustainability, which is a necessary component to successfully implement the practice of sustainable manufacturing in any organization. Considering this research gap, at first, this paper aims to decouple the severity of failure modes from the economical, societal and ecological point of view.

\subsection{Recent applications of MCDM methods in FMEA}

MCDM methods have been widely used to prioritize failure modes according to their risk levels in FMEA studies. The Technique for Order Preference by Similarity to Ideal Solution (TOPSIS) method, based on the idea of pairwise comparison has also been found to have its niche in conducting FMEA analysis. It has been combined with other methods, like Shannon's entropy principle and fuzzy logic [6], evidential reasoning [36], soft set theory [37], intuitionistic fuzzy logic [38], AHP [5], D-number [39], rough number [9], Support Vector Machine (SVM), fuzzy inference system and logarithmic fuzzy preference programming [40], and cloud model theory [41], etc. for more rationale decision-making. VlseKriterijumska Optimizacija I Kompromisno Resenje; a Serbian Word (VIKOR), developed as a Multi-criteria Optimization and Compromise Solution, is a compromise ranking method that has been also applied solely or in combination with other approaches, like Decision Making Trial and Evaluation Laboratory (DEMATEL) and AHP [4], fuzzy AHP and Entropy principle [42], Fuzzy Best-Worst Method (FBWM) and fuzzy proximity \& fuzzy similarity entropy [8], house of reliability and rough number [43], in the FMEA domain. There are also some articles based on the application of outranking based MCDM methods in FMEA, like ELECTRE combined with interval two-tuple linguistic fuzzy logic [44], ELCTRE-TRI based approach [45], hesitant 2-tuple linguistic qualitative flexible multiple criteria method (QUALIFLEX) [46], Preference Ranking Organization METHod for Enrichment of Evaluations (PROMETHEE) integrated with cloud model [47], etc. 
Apart from the above approaches, COmplex PRoportinal ASsessment (COPRAS) was integrated with the Grey number [34], and the interval valued intuitionistic fuzzy analytic network process (ANP), [48], to incorporate the inconsistency and vagueness of the decisions as well as to represent the interactions between failure modes and dependencies of the RFs. Further, the full multiplicative form of Multi-Objective Optimization by Ratio Analysis (MULTIMOORA) was extended to the fuzzy domain [49], and integrated with interval valued intuitionistic continuous weighted entropy [50], and the fuzzy AHP [51] method for making the decision-making approach simpler and robust. An effective behavioural decision making method derived from prospect theory - TODIM approach (an acronym in Portuguese for interactive and multi-criteria decision making) was extended to incorporate the linguistic distribution assessment in the FMEA domain to overcome some drawbacks of the traditional approach [7]. In [52], the Multi-Attributive Border-Approximation Area Comparison (MABAC) method was extended to interval-valued intuitionistic fuzzy sets to model the uncertainty and vagueness in a structured way. Moreover, they developed a linear programming model capable of determining the RF weight when the prior information available is incomplete. Recently, in [53] a newly developed MCDM method, Election based on Relative Value Distance (ERVD) was coupled with AHP for performing FMEA of an induction motor.

It is observed from the previous discussions that despite several benefits of IT2FS, so far it has not been applied in the FMEA domain. MAIRCA, being a new and potential method in the MCDM family, has not had any application in FMEA. Thus, this paper aims to present a novel hybrid MCGDM approach by using IT2F-DEMATEL and the modified FMAIRCA in the FMEA domain.

\section{Preliminaries}

The triangular fuzzy number and trapezoidal IT2FS are utilized in this proposed work. Therefore, some basic operations and definitions for both are briefly presented here for the sake of completeness and benefit of the reader.

\subsection{Fuzzy Number and Arithmetic Operations}

A fuzzy number is the special fuzzy set, which is represented as follows [15]:

$$
\tilde{A}=\left\{\left(x, \mu_{\tilde{A}}(x)\right), x \in R\right\},
$$

where $x$ represents the set of values on the real number line and $\mu_{\tilde{A}}(x)$ is the continuous mapping from $R$ to the closed interval. There are different kinds of fuzzy numbers and among them the triangular fuzzy number (TFN) is the most popular one due to its lower computational complexity and it has been used in those problems where a decision maker is not sure about the membership function of an alternative and/or criteria. A TFN is expressed as $\tilde{A}=\left(a_{l}, a_{m}, a_{u}\right)$. The membership function of this TFN is defined as:

$$
0, x<a_{l} \text { or } x>a_{u}
$$




$$
\begin{aligned}
\mu_{\tilde{A}}(x)= & \frac{x-a_{l}}{a_{m}-a_{l}}, a_{l} \leq x \leq a_{m} \\
& \frac{a_{u}-x}{a_{u}-a_{u}}, a_{m}<x \leq a_{u}
\end{aligned}
$$

1 Usually $a_{l} \leq a_{m} \leq a_{u}$, and $a_{l}, a_{m}$ and $a_{u}$ are known as the smallest possible value, most promising

2 value and largest possible value, respectively of a TFN $\tilde{A}$.

3 Basic arithmetic operations on TFN are:

$4 \quad$ Let two TFNs are $\tilde{A}=\left(a_{l}, a_{m}, a_{u}\right)$ and $\tilde{B}=\left(b_{l}, b_{m}, b_{u}\right)$.

Addition:

$$
\begin{gathered}
\tilde{A} \oplus \tilde{B}=\left(a_{l}+b_{l}, a_{m}+b_{m}, a_{u}+b_{u}\right) \\
\tilde{A} \Theta \tilde{B}=\left(a_{l}-b_{u}, a_{m}-b_{m}, a_{u}-b_{l}\right) \text { where } a_{i}>0, b_{i}>0 \\
\tilde{A} \otimes \tilde{B} \cong\left(a_{l} \times b_{l}, a_{m} \times b_{m}, a_{u} \times b_{u}\right) ; a_{l} \geq 0, b_{l} \geq 0 \\
\tilde{A} \oslash \tilde{B}=\left(a_{l} \div b_{u}, a_{m} \div b_{m}, a_{u} \div b_{l}\right) ; a_{l} \geq 0, b_{l}>0 \\
\lambda \tilde{A}=\left(\lambda \times a_{l}, \lambda \times a_{m}, \lambda \times a_{u}\right) ; \lambda>0 \\
\lambda \tilde{A}=\left(\lambda \times a_{u}, \lambda \times a_{m}, \lambda \times a_{l}\right) ; \lambda<0
\end{gathered}
$$

Subtraction:

Multiplication:

Division:

Multiplication

by a crisp

value:

\section{$5 \quad$ 3.2. Interval type-2 fuzzy sets}

6 Useful definitions of type-2 fuzzy set theory are described below [18]:

7 Definition 1: A type-2 fuzzy set (T2FS) $\widetilde{\widetilde{A}}$ in the universe of discourse $X$ is represented by Eq. (8) where

$8 \mu_{\tilde{A}}$ is a type-2 membership function,

$$
\tilde{\tilde{A}}=\left\{\left((x, u), \mu_{\tilde{\tilde{A}}}(x, u) \mid \forall x \in X, \forall u \in J_{x} \subseteq[0,1], 0 \leq \mu_{\tilde{A}}(x, u) \leq 1\right\}\right.
$$

$9 \quad$ where $J_{x}$ denotes an interval in[0,1]. A type-2 fuzzy set $\tilde{\tilde{A}}$ can also be represented as in Eq. (9)

$$
\tilde{\tilde{A}}=\int_{x \in X} \int_{u \in J_{x}} \mu_{\tilde{A}}(x, u) /(x, u)
$$

where $J_{x} \subseteq[0,1]$ and $\iint$ denotes union over all admissible $x$ and $u$.

Definition 2: Let $\tilde{\tilde{A}}$ be a T2FS in the universe of discourse $X$ represented by the type-2 membership function $\mu_{\tilde{A}}$. If all $\mu_{\tilde{A}}(x, u)=1$, then $\tilde{\tilde{A}}$ is called an IT2FS. An IT2FS $\tilde{\tilde{A}}$ can be regarded as a special case of a type-2 fuzzy set, represented as follows:

$$
\tilde{\tilde{A}}=\int_{x \in X} \int_{u \in J_{x}} 1 /(x, u)
$$

where $J_{x} \subseteq[0,1]$

In other words, if all the secondary grades are equal to 1, then T2 FS is known as IT2FS.

Definition 3: The upper membership function and the lower membership function of an IT2FS are type1 membership functions, respectively. Refer to Figure 1, which shows a trapezoidal IT2FS $\tilde{\tilde{A}}$ as given 8 in Eq. (11). In other words, when the upper membership function and lower membership function of an 19 IT2FS are of linear type, it can be known as the trapezoidal IT2FS. 


$$
\tilde{\tilde{A}}=\left(\tilde{A}_{i}^{U}, \tilde{A}_{i}^{L}\right)=\left(\left(a_{i 1}^{U}, a_{i 2}^{U}, a_{i 3}^{U}, a_{i 4}^{U} ; H_{1}\left(\tilde{A}_{i}^{U}\right), H_{2}\left(\tilde{A}_{i}^{U}\right),\left(a_{i 1}^{L}, a_{i 2}^{L}, a_{i 3}^{L}, a_{i 4}^{L} ; H_{1}\left(\tilde{A}_{i}^{L}\right), H_{2}\left(\tilde{A}_{i}^{L}\right)\right)\right.\right.
$$

$3 \tilde{A}_{i}^{U}$ and $\tilde{A}_{i}^{L}$ are type-1 fuzzy sets, $a_{i 1}^{U}, a_{i 2}^{U}, a_{i 3}^{U}, a_{i 4}^{U}, a_{i 1}^{L}, a_{i 2}^{U}, a_{i 3}^{U}$ and $a_{i 4}^{L}$ are the reference points of IT2FS $4 \quad \widetilde{\widetilde{A}}_{l} . H_{j}\left(\tilde{A}_{i}^{U}\right)$ denotes the membership value of the element $a_{j(j+1)}^{U}$ in the upper trapezoidal membership 5 function $\left(\tilde{A}_{i}^{U}\right)$, where $1 \leq j \leq 2 . H_{j}\left(\tilde{A}_{i}^{L}\right)$ denotes the membership value of the element $a_{j(j+1)}^{L}$ in the 6 7

lower trapezoidal membership function $\left(\tilde{A}_{i}^{L}\right)$, where $1 \leq j \leq 2 . \quad H_{1}\left(\tilde{A}_{i}^{U}\right) \in[0,1], H_{2}\left(\tilde{A}_{i}^{U}\right) \in$ $7 \quad[0,1], H_{1}\left(\tilde{A}_{i}^{L}\right) \in[0,1], H_{2}\left(\tilde{A}_{i}^{L}\right) \in[0,1]$ and $1 \leq i \leq n$.

\section{Arithmetic operations}

Let two trapezoidal IT2FSs be,

$\tilde{\tilde{A}}_{1}=\left(\left(a_{11}^{U}, a_{12}^{U}, a_{13}^{U}, a_{14}^{U} ; H_{1}\left(\tilde{A}_{1}^{U}\right), H_{2}\left(\tilde{A}_{1}^{U}\right),\left(a_{11}^{L}, a_{12}^{L}, a_{13}^{L}, a_{14}^{L} ; H_{1}\left(\tilde{A}_{1}^{L}\right), H_{2}\left(\tilde{A}_{1}^{L}\right)\right)\right.\right.$, and $\tilde{\tilde{A}}_{2}=\left(\left(a_{21}^{U}, a_{22}^{U}, a_{23}^{U}, a_{24}^{U} ; H_{1}\left(\tilde{A}_{2}^{U}\right), H_{2}\left(\tilde{A}_{2}^{U}\right),\left(a_{21}^{L}, a_{22}^{L}, a_{23}^{L}, a_{24}^{L} ; H_{1}\left(\tilde{A}_{2}^{L}\right), H_{2}\left(\tilde{A}_{2}^{L}\right)\right)\right.\right.$.

Definition 4 (Addition): The addition operation between the trapezoidal IT2FSs is defined as follows:

$$
\begin{aligned}
\tilde{\tilde{A}}_{1} \oplus \tilde{\tilde{A}}_{2}=\left(\left(a_{11}^{U}\right.\right. & +a_{21}^{U}, a_{12}^{U}+a_{22}^{U}, a_{13}^{U}+a_{23}^{U}, a_{14}^{U} \\
& \left.+a_{24}^{U} ; \min \left(H_{1}\left(\tilde{A}_{1}^{U}\right) ; H_{1}\left(\tilde{A}_{2}^{U}\right)\right), \min \left(H_{2}\left(\tilde{A}_{1}^{U}\right) ; H_{2}\left(\tilde{A}_{2}^{U}\right)\right)\right),\left(a_{11}^{L}+a_{21}^{L}, a_{12}^{L}\right. \\
& +a_{22}^{L}, a_{13}^{L}+a_{23}^{L}, a_{14}^{L} \\
& \left.\left.+a_{24}^{L} ; \min \left(H_{1}\left(\tilde{A}_{1}^{L}\right) ; H_{1}\left(\tilde{A}_{2}^{L}\right)\right), \min \left(H_{2}\left(\tilde{A}_{1}^{L}\right) ; H_{2}\left(\tilde{A}_{2}^{L}\right)\right)\right)\right)
\end{aligned}
$$

Definition 5 (Subtraction): The subtraction operator between two trapezoidal IT2FSs is carried out as follows:

$$
\begin{aligned}
\tilde{\tilde{A}}_{1} \ominus \tilde{\tilde{A}}_{2}=(( & a_{11}^{U}-a_{24}^{U}, a_{12}^{U}-a_{23}^{U}, a_{13}^{U}-a_{22}^{U}, a_{14}^{U} \\
& \left.-a_{21}^{U} ; \min \left(H_{1}\left(\tilde{A}_{1}^{U}\right) ; H_{1}\left(\tilde{A}_{2}^{U}\right)\right), \min \left(H_{2}\left(\tilde{A}_{1}^{U}\right) ; H_{2}\left(\tilde{A}_{2}^{U}\right)\right)\right),\left(a_{11}^{L}-a_{24}^{L}, a_{12}^{L}\right. \\
& -a_{23}^{L}, a_{13}^{L}-a_{22}^{L}, a_{14}^{L} \\
& \left.\left.-a_{21}^{L} ; \min \left(H_{1}\left(\tilde{A}_{1}^{L}\right) ; H_{1}\left(\tilde{A}_{2}^{L}\right)\right), \min \left(H_{2}\left(\tilde{A}_{1}^{L}\right) ; H_{2}\left(\tilde{A}_{2}^{L}\right)\right)\right)\right)
\end{aligned}
$$

Definition 6 (Multiplication): The multiplication operation between two IT2FS is carried out as follows:

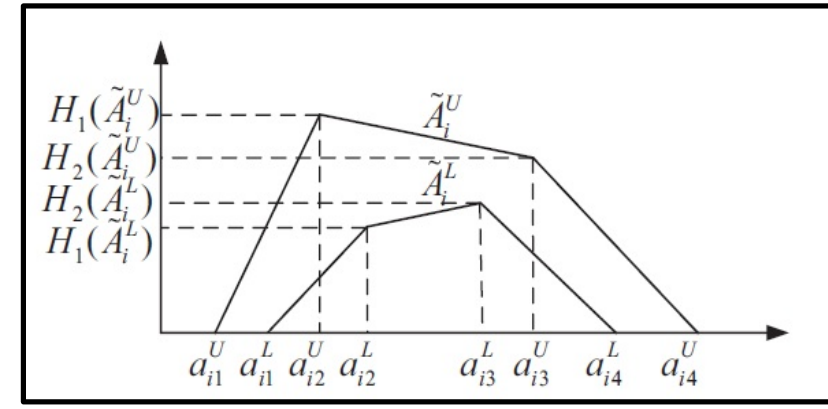

Figure 1. A trapezoidal type-2 fuzzy set [18] 


$$
\begin{aligned}
\tilde{\tilde{A}}_{1} \otimes \tilde{\tilde{A}}_{2} \cong\left(\left(a_{11}^{U}\right.\right. & \times a_{21}^{U}, a_{12}^{U} \times a_{22}^{U}, a_{13}^{U} \times a_{23}^{U}, a_{14}^{U} \\
& \left.\times a_{24}^{U} ; \min \left(H_{1}\left(\tilde{A}_{1}^{U}\right) ; H_{1}\left(\tilde{A}_{2}^{U}\right)\right), \min \left(H_{2}\left(\tilde{A}_{1}^{U}\right) ; H_{2}\left(\tilde{A}_{2}^{U}\right)\right)\right),\left(a_{11}^{L} \times a_{21}^{L}, a_{12}^{L}\right. \\
& \times a_{22}^{L}, a_{13}^{L} \times a_{23}^{L}, a_{14}^{L} \\
& \left.\left.\times a_{24}^{L} ; \min \left(H_{1}\left(\tilde{A}_{1}^{L}\right) ; H_{1}\left(\tilde{A}_{2}^{L}\right)\right), \min \left(H_{2}\left(\tilde{A}_{1}^{L}\right) ; H_{2}\left(\tilde{A}_{2}^{L}\right)\right)\right)\right)
\end{aligned}
$$

1 Definition 7 (Scaling of IT2FSs): Multiplication and division of a crisp value with a trapezoidal IT2FS

2 yields the following equations:

$$
\begin{aligned}
& \tilde{\tilde{A}}_{1} \times k=\left(\left(a_{11}^{U} \times k, a_{12}^{U} \times k, a_{13}^{U} \times k, a_{14}^{U} \times k ; H_{1}\left(\tilde{A}_{1}^{U}\right), H_{2}\left(\tilde{A}_{1}^{U}\right),\left(a_{11}^{L} \times k, a_{12}^{L} \times k, a_{13}^{L}\right.\right.\right. \\
& \left.\quad \times k, a_{14}^{L} \times k ; H_{1}\left(\tilde{A}_{1}^{L}\right), H_{2}\left(\tilde{A}_{1}^{L}\right)\right) \\
& \frac{\tilde{\tilde{A}}_{1}}{k}=\left(\left(a_{11}^{U} \times \frac{1}{k}, a_{12}^{U} \times \frac{1}{k}, a_{13}^{U} \times \frac{1}{k}, a_{14}^{U} \times \frac{1}{k} ; H_{1}\left(\tilde{A}_{1}^{U}\right), H_{2}\left(\tilde{A}_{1}^{U}\right),\left(a_{11}^{L} \times \frac{1}{k}, a_{12}^{L} \times \frac{1}{k}, a_{13}^{L}\right.\right.\right. \\
& \left.\quad \times \frac{1}{k}, a_{14}^{L} \times \frac{1}{k} ; H_{1}\left(\tilde{A}_{1}^{L}\right), H_{2}\left(\tilde{A}_{1}^{L}\right)\right)
\end{aligned}
$$

3 Definition 8 (Expected value of an IT2FSs): Expected value of a trapezoidal IT2FS $\tilde{\tilde{A}}_{1}$ is calculated as follows:

$$
E(A)=\frac{1}{2}\left(\frac{1}{4} \sum_{i=1}^{4}\left(a_{i}^{L}+a_{i}^{U}\right)\right) \times \frac{1}{4}\left(\sum_{i=1}^{2}\left(H_{i}\left(A^{L}\right)+H_{i}\left(A^{U}\right)\right)\right)
$$

$5 \quad$ where $\tilde{\tilde{A}}=\left(\left(a_{1}^{U}, a_{2}^{U}, a_{3}^{U}, a_{4}^{U} ; H_{1}\left(\tilde{A}^{U}\right), H_{2}\left(\tilde{A}^{U}\right)\right),\left(a_{1}^{L}, a_{2}^{L}, a_{3}^{L}, a_{4}^{L} ; H_{1}\left(\tilde{A}^{L}\right), H_{2}\left(\tilde{A}^{L}\right)\right)\right)$.

\section{4. The proposed methodology}

7 The proposed methodology consists of four steps, viz.

8 i. Structuring the problem

9 ii. Modelling the interactions between criteria by IT2FS-DEMATEL

10 iii. Deriving the weights of the criteria by IT2FS-DEMATEL

11 iv. Ranking of the alternatives by our proposed FMARICA

A detailed view of the above steps is shown in Figure 2 and is elaborated in the succeeding paragraphs.

\subsection{Structuring the problem}

In this step, the goal and scope of the study is defined. Subsequently, cross-functional experts are chosen by top management and they decide on criteria, sub-criteria and major alternatives of the problem being considered. The problem is depicted in a hierarchical structure for ease of decision making. Also, linguistic variables and their associated IT2FSs values are assigned/chosen.

\subsection{Interval type-2 fuzzy DEMATEL}

Major steps of IT22FS-DEMATEL are as follows [18]: 
- Step 2: Calculating the average of the IT2F influence matrix as in Eq. (18).

$$
\tilde{\tilde{Y}}=\frac{\tilde{\tilde{Y}}^{(1)} \oplus \tilde{\tilde{Y}}^{(2)} \oplus \tilde{\tilde{Y}}^{(3)} \oplus \ldots \oplus \tilde{\tilde{Y}}^{(k)}}{k}
$$

5

Here $\tilde{\tilde{Y}}$ represents initial direct relation matrix. This matrix is seen as Eq. (19),

$$
\tilde{\tilde{Y}}=\left[\begin{array}{cccc}
0 & \tilde{\tilde{y}}_{12} & \cdots & \tilde{\tilde{y}}_{1 m} \\
\tilde{\tilde{y}}_{21} & \ddots & & \vdots \\
\vdots & & & \\
\tilde{\tilde{y}}_{m 1} & \tilde{\tilde{y}}_{m 2} & \cdots & 0
\end{array}\right]
$$

where $\tilde{\tilde{y}}_{i j}=\left(\left(a_{i j}, b_{i j}, c_{i j}, d_{i j} ; H_{1}\left(\tilde{y}_{i j}^{U}\right), H_{2}\left(\tilde{y}_{i j}^{U}\right)\right),\left(e_{i j}, f_{i j}, g_{i j}, h_{i j} ; H_{1}\left(\tilde{y}_{i j}^{L}\right), H_{2}\left(\tilde{y}_{i j}^{L}\right)\right)\right)$

- Step 3: In this step, the normalized direct relation matrix is obtained. To do that, the initial trapezoidal IT2FS direct relation matrix based on the membership function is recognized. It is observed that heights of IT2FNs do not affect the results and hence they are omitted from the subsequent calculations. A total of eight $m \times m$ matrices are constructed as follows:

$$
\begin{aligned}
& Y_{a^{\prime}}=\left[\begin{array}{cccc}
0 & a_{12}^{\prime} & \cdots & a_{1 m}^{\prime} \\
a_{21}^{\prime} & & & a_{2 m}^{\prime} \\
\vdots & & & \vdots \\
a_{m 1}^{\prime} & a_{m 2}^{\prime} & \cdots & 0
\end{array}\right] \\
& Y_{b^{\prime}}=\left[\begin{array}{crcc}
0 & b_{12}^{\prime} & \cdots & b_{1 m}^{\prime} \\
b_{21}^{\prime} & & & b_{2 m}^{\prime} \\
\vdots & & & \vdots \\
b_{m 1}^{\prime} & b_{m 2}^{\prime} & \cdots & 0
\end{array}\right] \\
& \text { : } \\
& Y_{h^{\prime}}=\left[\begin{array}{crcc}
0 & h_{12}^{\prime} & \cdots & h_{1 m}^{\prime} \\
h_{21}^{\prime} & & & h_{2 m}^{\prime} \\
\vdots & & & \vdots \\
h_{m 1}^{\prime} & h_{m 2}^{\prime} & \cdots & 0
\end{array}\right]
\end{aligned}
$$

As $Y_{d^{\prime}}$ contains the greatest element, we use it further for calculating the normalization coefficients. The normalized direct relation matrix is represented by Eq. (21):

$$
\widetilde{\widetilde{N}}=\left[\begin{array}{cccc}
\tilde{\tilde{n}}_{11} & \tilde{\tilde{n}}_{12} & \cdots & \tilde{\tilde{n}}_{1 m} \\
\tilde{\tilde{n}}_{21} & & & \tilde{\tilde{n}}_{2 m} \\
\vdots & & & \vdots \\
\tilde{\tilde{n}}_{m 1} & \tilde{\tilde{n}}_{m 2} & \cdots & \tilde{\tilde{n}}_{m m}
\end{array}\right]
$$

Elements of the normalized direct-relation matrix are calculated as follows: 


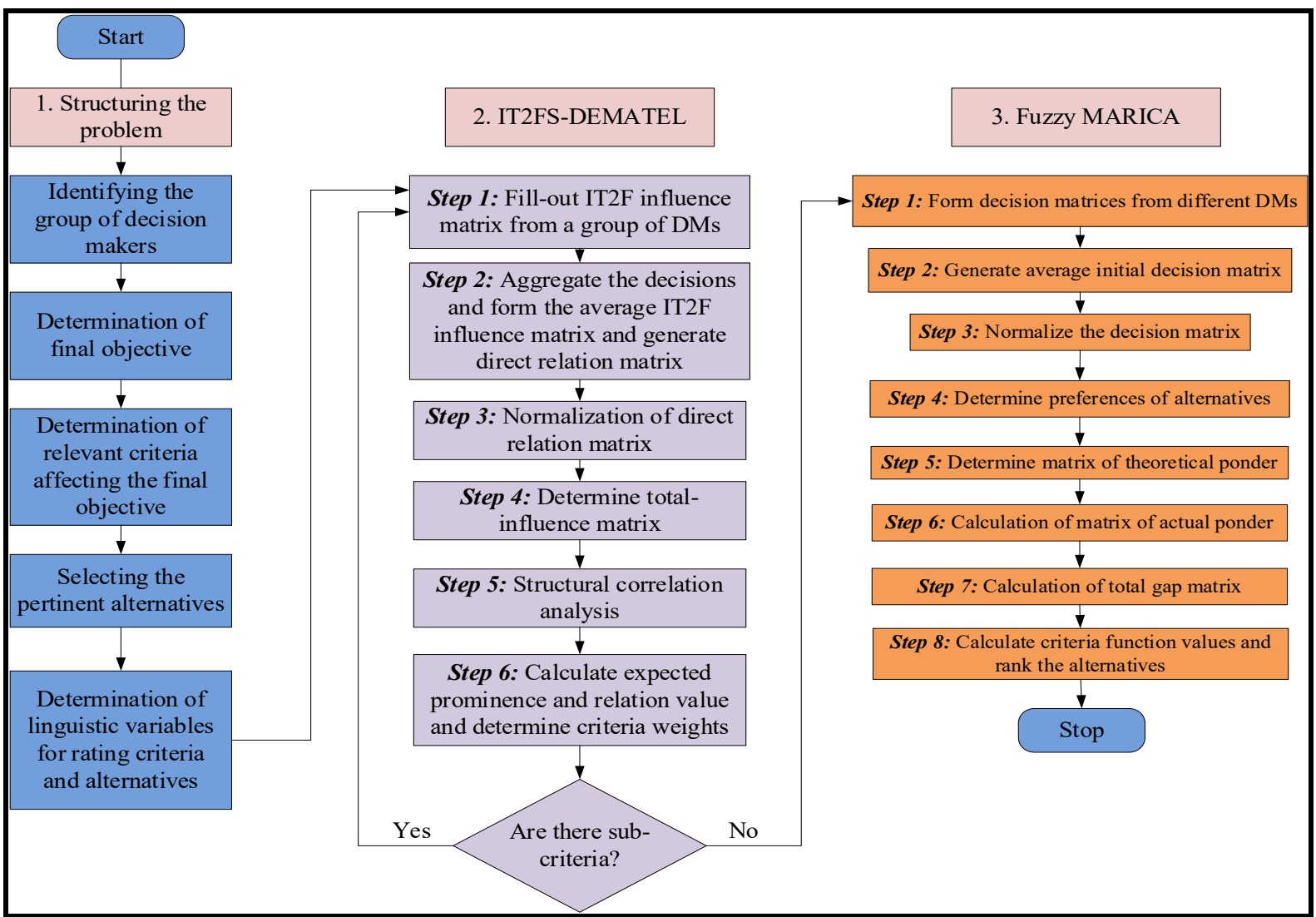

Figure 2. Workflow diagram of proposed MCGDM framework

$$
\begin{aligned}
\tilde{\tilde{n}}_{i j}=\frac{\tilde{y}_{i j}}{v}= & \left(\left(\frac{Y_{a_{i j}^{\prime}}}{v}, \frac{Y_{b_{i j}^{\prime}}}{v}, \frac{Y_{c_{i j}^{\prime}}}{v}, \frac{Y_{d_{i j}^{\prime}}}{v} ; H_{1}\left(\tilde{y}_{i j}^{U}\right), H_{2}\left(\tilde{y}_{i j}^{U}\right)\right)\right. \\
& \left.\times\left(\frac{Y_{e_{i j}^{\prime}}}{v}, \frac{Y_{f_{i j}^{\prime}}}{v}, \frac{Y_{g_{i j}^{\prime}}}{v}, \frac{Y_{h_{i j}^{\prime}}}{v} ; H_{1}\left(\tilde{y}_{i j}^{L}\right), H_{2}\left(\tilde{y}_{i j}^{L}\right)\right)\right)
\end{aligned}
$$

The normalization coefficient $\mathrm{t}$ is calculated as follows:

$$
v=\max \left(\max _{1 \leq i \leq m} \sum_{j=1}^{m} Y_{d_{i j}^{\prime}, 1 \leq j \leq m} \sum_{i=1}^{m} Y_{d_{i j}^{\prime}}\right)
$$

- Step 4: Obtain the total relation matrix in a similar fashion as in Step 3, where the normalized direct-relation matrix represented by eight crisp matrices are:

$$
\begin{aligned}
N_{a^{\prime \prime}} & =\left[\begin{array}{cccc}
0 & a_{12}^{\prime \prime} & \cdots & a_{1 m}^{\prime \prime} \\
a_{21}^{\prime \prime} & \ddots & & a_{2 m}^{\prime \prime} \\
\vdots & & & \vdots \\
a_{m 1}^{\prime \prime} & a_{m 2}^{\prime \prime} & \cdots & 0
\end{array}\right] \\
N_{b^{\prime \prime}} & =\left[\begin{array}{cccc}
0 & b_{12}^{\prime \prime} & \cdots & b_{1 m}^{\prime \prime} \\
b_{21}^{\prime \prime} & \ddots & & b_{2 m}^{\prime \prime} \\
\vdots & & & \vdots \\
b_{m 1}^{\prime \prime} & b_{m 2}^{\prime \prime} & \cdots & 0
\end{array}\right]
\end{aligned}
$$




$$
N_{h^{\prime \prime}}=\left[\begin{array}{cccc}
0 & h_{12}^{\prime \prime} & \cdots & h_{1 m}^{\prime \prime} \\
h_{21}^{\prime \prime} & & & h_{2 m}^{\prime \prime} \\
\vdots & & & \vdots \\
h_{m 1}^{\prime \prime} & h_{m 2}^{\prime \prime} & \cdots & 0
\end{array}\right]
$$

The total relation matrix $\tilde{\tilde{T}}$ is represented as follows:

$$
\tilde{\tilde{T}}=\left[\begin{array}{cccc}
\tilde{\tilde{t}}_{11} & \tilde{\tilde{t}}_{12} & \cdots & \tilde{\tilde{t}}_{1 m} \\
\tilde{\tilde{t}}_{21} & & & \tilde{\tilde{t}}_{2 m} \\
\vdots & & & \vdots \\
\tilde{t}_{m 1} & \tilde{\tilde{t}}_{m 2} & \cdots & \tilde{\tilde{t}}_{m m}
\end{array}\right]
$$

where, $\tilde{\tilde{t}}_{i j}=\left(\left(a_{i j}^{\prime \prime \prime}, b_{i j}^{\prime \prime \prime}, c_{i j}^{\prime \prime \prime}, d_{i j}^{\prime \prime \prime} ; H_{1}\left(\tilde{t}_{i j}^{U}\right), H_{2}\left(\tilde{t}_{i j}^{U}\right)\right),\left(e_{i j}^{\prime \prime \prime}, f_{i j}^{\prime \prime \prime}, g_{i j}^{\prime \prime \prime}, h_{i j}^{\prime \prime \prime} ; H_{1}\left(\tilde{t}_{i j}^{L}\right), H_{2}\left(\tilde{t}_{i j}^{L}\right)\right)\right)$.

The elements of the matrix in Eq. (25) are calculated as follows:

$$
\begin{gathered}
{\left[a_{i j}^{\prime \prime \prime}\right]=N_{a^{\prime \prime}} \times\left(I-N_{a^{\prime \prime}}\right)^{-1}} \\
{\left[b_{i j}^{\prime \prime \prime}\right]=N_{b^{\prime \prime}} \times\left(I-N_{b^{\prime \prime}}\right)^{-1}} \\
\vdots \\
{\left[h_{i j}^{\prime \prime \prime}\right]=N_{h^{\prime \prime}} \times\left(I-N_{h^{\prime \prime}}\right)^{-1}}
\end{gathered}
$$

- Step 5: To conduct the structural correlational analysis, the elements of the total-relation matrix $\tilde{t}_{i j}$ are used. Sum of the columns and sum of the rows of $\tilde{\tilde{T}}$ are denoted by $\tilde{\tilde{R}}_{j}$ and $\widetilde{\widetilde{D}}_{i}$, and represented by Eq. (27) and Eq. (28), respectively.

$$
\begin{aligned}
& \tilde{\tilde{R}}_{j}=\sum_{i=1}^{m} \tilde{\tilde{t}}_{i j} \text { where } j=1,2,3, \ldots, m \\
& \widetilde{\widetilde{D}}_{i}=\sum_{i=1}^{m} \tilde{\tilde{t}}_{i j} \text { where } i=1,2,3, \ldots, m
\end{aligned}
$$

To draw the causal diagram, expected values of the ordered pairs $\left(\widetilde{\widetilde{D}}_{i} \oplus \tilde{\tilde{R}}_{i}\right)$ and $\left(\widetilde{\widetilde{D}}_{i} \ominus \tilde{\widetilde{R}}_{i}\right)$ are calculated.

- Step 6: Importance of each criterion is calculated as in Eq. (29):

$$
w_{i}=\sqrt{\left(E\left(\widetilde{\widetilde{D}}_{i} \oplus \tilde{\tilde{R}}_{i}\right)\right)^{2}+\left(E\left(\widetilde{\widetilde{D}}_{i} \ominus \tilde{\tilde{R}}_{i}\right)\right)^{2}}
$$

$E\left(\widetilde{\widetilde{D}}_{i} \oplus \tilde{\tilde{R}}_{i}\right)=$ Expected prominence and $E\left(\widetilde{\widetilde{D}}_{i} \ominus \tilde{\widetilde{R}}_{i}\right)=$ expected relation.

Finally, the normalized importance degree of each criterion is calculated as in Eq. (30):

$$
n w_{i}=\frac{w_{i}}{\sum_{i=1}^{m} w_{i}}
$$

Sub attribute weights are calculated in a similar fashion as the calculation of the main attribute weights and finally they are multiplied to get the overall weights. 
2 Following steps are necessary to carry out the FMARICA procedure:

- Step 1: Define the initial decision matrices, where $m$ alternatives are initially evaluated with respect of the $n$ number of criteria in linguistic terms. Later, these values are converted to TFN by following any suitable and agreed scale, such as in Table 7, shown later in Section 4. Initial decision matrices are represented by Eq. (31):

$$
\begin{aligned}
& \widetilde{D}^{1}=\left[\begin{array}{cccccc}
\tilde{d}_{11}^{(1)} & \tilde{d}_{12}^{(1)} & \tilde{d}_{13}^{(1)} & \ldots & & \tilde{d}_{1 n}^{(1)} \\
\tilde{d}_{21}^{(1)} & \tilde{d}_{22}^{(1)} & \tilde{d}_{23}^{(1)} & \ldots & & \tilde{d}_{2 n}^{(1)} \\
\vdots & & \ddots & & \\
\tilde{d}_{(m-1) 1}^{(1)} & \tilde{d}_{(m-1) 2}^{(1)} & \tilde{d}_{(m-1) 3}^{(1)} & \ldots & \tilde{d}_{(m-1) n}^{(1)} \\
\tilde{d}_{m 1}^{(1)} & \tilde{d}_{m 2}^{(1)} & \tilde{d}_{m 3}^{(1)} & \ldots & \tilde{d}_{m n}^{(1)}
\end{array}\right] \\
& \widetilde{D}^{2}=\left[\begin{array}{cccccc}
\tilde{d}_{11}^{(2)} & \tilde{d}_{12}^{(2)} & \tilde{d}_{13}^{(2)} & \ldots & & \tilde{d}_{1 n}^{(2)} \\
\tilde{d}_{21}^{(2)} & \tilde{d}_{22}^{(2)} & \tilde{d}_{23}^{(2)} & \cdots & & \tilde{d}_{2 n}^{(2)} \\
\vdots & & \ddots & & & \vdots \\
\tilde{d}_{(m-1) 1}^{(2)} & \tilde{d}_{(m-1) 2}^{(2)} & \tilde{d}_{(m-1) 3}^{(2)} & \cdots & \tilde{d}_{(m-1) n}^{(2)} \\
\tilde{d}_{m 1}^{(2)} & \tilde{d}_{m 2}^{(2)} & \tilde{d}_{m 3}^{(2)} & \cdots & \tilde{d}_{m n}^{(2)}
\end{array}\right] \\
& \widetilde{D}^{k}=\left[\begin{array}{cccccc}
\tilde{d}_{11}^{(k)} & \tilde{d}_{12}^{(k)} & \tilde{d}_{13}^{(k)} & \ldots & & \tilde{d}_{1 n}^{(k)} \\
\tilde{d}_{21}^{(k)} & \tilde{d}_{22}^{(k)} & \tilde{d}_{23}^{(k)} & \cdots & & \tilde{d}_{2 n}^{(k)} \\
\vdots & & \ddots & & & \vdots \\
\tilde{d}_{(m-1) 1}^{(k)} & \tilde{d}_{(m-1) 2}^{(k)} & \tilde{d}_{(m-1) 3}^{(k)} & \ldots & \tilde{d}_{(m-1) n}^{(k)} \\
\tilde{d}_{m 1}^{(k)} & \tilde{d}_{m 2}^{(k)} & \tilde{d}_{m 3}^{(k)} & \cdots & \tilde{d}_{m n}^{(k)}
\end{array}\right]
\end{aligned}
$$

where $\tilde{d}_{i j}^{(k)}=\left(d_{l}^{k}, d_{m}^{k}, d_{u}^{k}\right) ; d_{l} \leq d_{m} \leq d_{u} ; i=1,2,3, \ldots, m ; j=1,2,3, \ldots n ; k=$ number of decision makers.

- Step 2: Aggregation of decisions provided by the decision makers and construct the average of

where $\tilde{d}_{i j}^{(f)}=\frac{\left(\tilde{d}_{i j}^{(1)}+\tilde{d}_{i j}^{(2)}+\ldots+\tilde{d}_{i j}^{(k)}\right)}{k}$

- Step 3: Decision matrix $\widetilde{D}^{F}$ is normalized for each of the criterion. Here a different type of normalization technique, instead of the technique given in [19] is used to reduce the efforts of hard computation and to improve the accuracy of numeration. Furthermore, for large number of 
criteria, it is difficult for the decision makers to identify the cost and benefit type of criterion, which is discarded after using this technique. Eq. (33) is used in the fuzzy domain for carrying out the normalization of aggregated data:

$$
\begin{aligned}
& n_{i j}^{l}=\frac{d_{i j}^{l}}{\sqrt{\sum_{i=1}^{m}\left[\left(d_{i j}^{l}\right)^{2}+\left(d_{i j}^{m}\right)^{2}+\left(d_{i j}^{u}\right)^{2}\right]}} \\
& n_{i j}^{m}=\frac{d_{i j}^{m}}{\sqrt{\sum_{i=1}^{m}\left[\left(d_{i j}^{l}\right)^{2}+\left(d_{i j}^{m}\right)^{2}+\left(d_{i j}^{u}\right)^{2}\right]}} \\
& n_{i j}^{u}=\frac{d_{i j}^{u}}{\sqrt{\sum_{i=1}^{m}\left[\left(d_{i j}^{l}\right)^{2}+\left(d_{i j}^{m}\right)^{2}+\left(d_{i j}^{u}\right)^{2}\right]}}
\end{aligned}
$$

The normalized decision matrix looks like the following:

$$
\widetilde{N}=\left[\begin{array}{cccccc}
\tilde{n}_{11} & \tilde{n}_{12} & \tilde{n}_{13} & \cdots & & \tilde{n}_{1 n} \\
\tilde{n}_{21} & \tilde{n}_{22} & \tilde{n}_{13} & \cdots & & \tilde{n}_{2 n} \\
\vdots & & \ddots & & & \vdots \\
\tilde{n}_{(m-1) 1} & \tilde{n}_{(m-1) 1} & \tilde{n}_{(m-1) 3} & \cdots & \tilde{n}_{(m-1) n} \\
\tilde{n}_{m 1} & \tilde{n}_{m 2} & \tilde{n}_{m 3} & \cdots & \tilde{n}_{m n}
\end{array}\right]
$$

- Step 4: Next, the preferences to the selection of alternatives are defined as in Eq. (35). It is ensured that each of the alternatives are given equal preference for selection as the optimum one.

$$
P_{D_{i}}=\frac{1}{m} ; \sum_{i=1}^{m} P_{D_{i}}=1
$$

where, $m=$ number of alternatives.

- Step 5: For the sake of ease in calculation, criteria weights are considered as fuzzy numbers, where $\widetilde{w}_{i}=\left(w_{i}^{l}, w_{i}^{m}, w_{i}^{u}\right) ; w_{i}^{l}=w_{i}^{m}=w_{i}^{u}$. It is also possible to convert the IT2 criteria weight to the $\mathrm{T} 1$ criteria weight by using any type reduction approach [54]. The fuzzy matrix of theoretical ponder $\left(\widetilde{T}_{p}\right)$ is determined by the following equation:

$$
\widetilde{T}_{p}=\left[\begin{array}{ccccc}
\frac{1}{m} \times \widetilde{w}_{1} & \frac{1}{m} \times \widetilde{w}_{2} & \frac{1}{m} \times \widetilde{w}_{3} & \ldots & \frac{1}{m} \times \widetilde{w}_{n} \\
\frac{1}{m} \times \widetilde{w}_{1} & \frac{1}{m} \times \widetilde{w}_{2} & \frac{1}{m} \times \widetilde{w}_{3} & \ldots & \frac{1}{m} \times \widetilde{w}_{n} \\
\vdots & & \ddots & & \vdots \\
\frac{1}{m} \times \widetilde{w}_{1} & \frac{1}{m} \times \widetilde{w}_{2} & \frac{1}{m} \times \widetilde{w}_{3} & \ldots & \frac{1}{m} \times \widetilde{w}_{n} \\
\frac{1}{m} \times \widetilde{w}_{1} & \frac{1}{m} \times \widetilde{w}_{2} & \frac{1}{m} \times \widetilde{w}_{3} & & \frac{1}{m} \times \widetilde{w}_{n}
\end{array}\right]
$$

where, $\tilde{t}_{p_{i j}}=\frac{1}{m} \times \widetilde{w}_{j}$, where $i=1,2,3, \ldots, m$ and $j=1,2,3, \ldots, n$. 
- Step 6: Calculation of matrix elements of actual ponder $\tilde{T}_{r}$ which is calculated by following Eq. (37). Each element is denoted by $\tilde{t}_{r_{i j}}$ :

$$
\tilde{T}_{r}=\left(\widetilde{N} \otimes \tilde{T}_{p}\right)
$$

- Step 7: Total gap matrix $(G)$ is calculated by using the notion of fuzzy Euclidean distance for each criterion from the theoretical and actual ponder matrix as shown in Eq. (38). By using this, the necessity of de-fuzzification for calculating the criteria function is eliminated. Each of the elements $G$ is denoted by $g_{i j}$ :

$$
[G]_{m \times n}=\left[\sqrt{\frac{1}{3}\left[\left(t_{p_{i j}}^{l}-t_{r_{i j}}^{l}\right)^{2}+\left(t_{p_{i j}}^{m}-t_{r_{i j}}^{m}\right)^{2}+\left(t_{p_{i j}}^{u}-t_{r_{i j}}^{u}\right)^{2}\right]}\right]_{m \times n}
$$

- Step 8: Final values of criterion functions for each of the alternatives are calculated by summing up the gap values as represented by Eq. (39):

$$
Q_{i}=\sum_{j=1}^{n} g_{i j} \text { where } i=1,2,3, \ldots, m
$$

The alternative with the lowest gap distance is selected as the best one, whereas the alternative with the highest gap distance is considered as the worst one.

\section{Case Study}

\subsection{Description of the problem}

A gearbox used in a steel processing plant (light medium and merchant mill section) is considered as a potential case study of the proposed approach. The block diagram of the considered gearbox is shown in Figure 3. In this section of the plant, the final shapes and sizes to the red-hot cast blooms are given. A total of seven gearboxes are arranged sequentially to produce the final output. These gearboxes operate in a harsh industrial environment, where ambient temperature, humidity, dust level and surrounding vibration are significantly higher than normal. Each of these gearboxes are critical in terms of operational and production points of view. The failure of anyone of them not only damages the quality of the final billet with a large economical loss but can also cause a major accident by severely injuring the operator(s) and may even lead to their death. Due to the strict sustainable regulations from the government and to facilitate the sustainable manufacturing practices, the organization is aiming to analyse the failure modes of the different components of the gearboxes, their effects on economical, social and environmental aspects. 


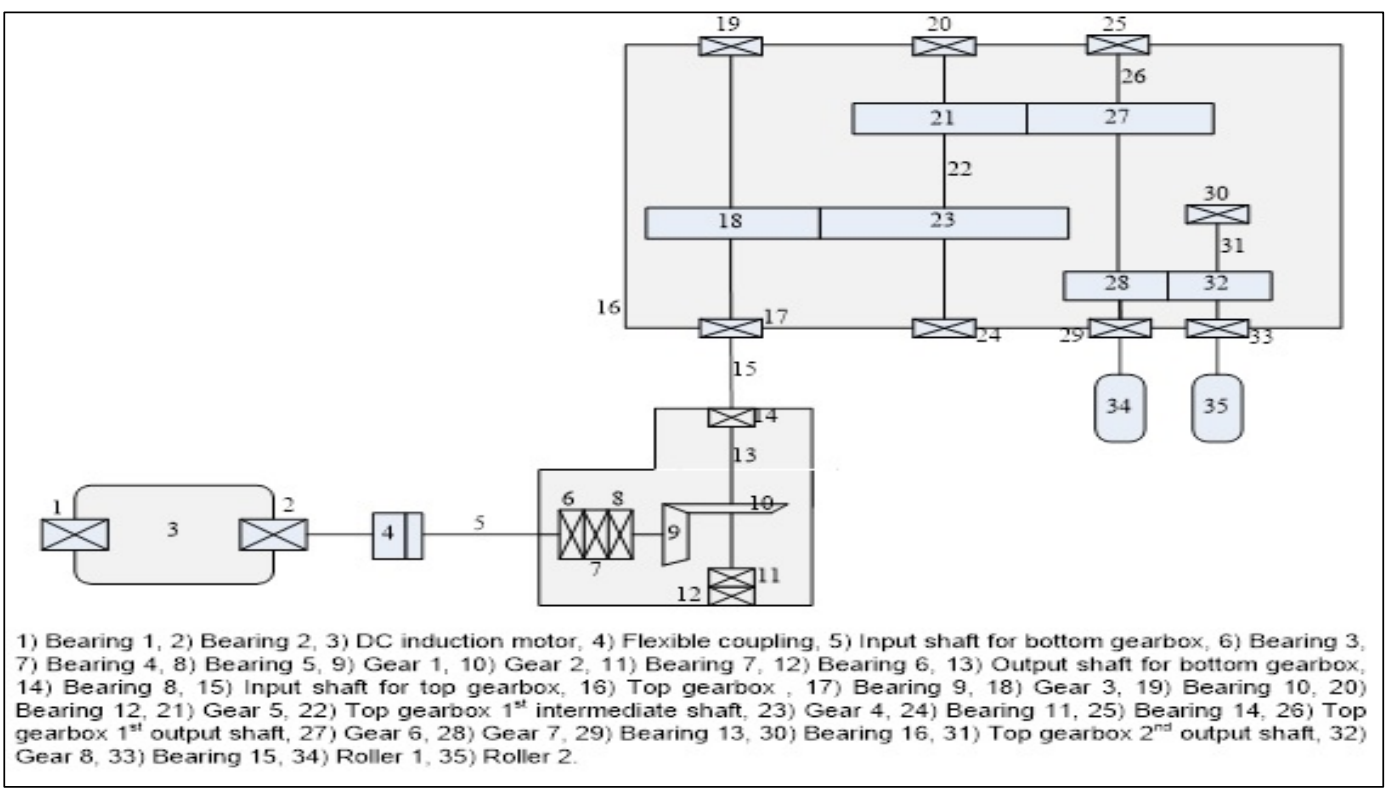

Figure 3. Schematic diagram of considered gearbox [55]

\subsection{Structuring the problem}

Three cross-functional experts were identified by the organization: one from top management (DM1), and another two are the chief workshop manager (DM2) and a workshop engineer (DM3), respectively. For the sake of simplicity in mathematical calculations, equal weightages are assigned to these experts. However, different weightages to the cross-functional experts can be given as shown in [1]. Later, these experts are asked to identify the most commonly occurring failure modes, their causes, effects (refer Table 1) and risk factors (refer Figure 4).

\subsection{Evaluating the causal dependencies and relative importance among risk factors by IT2F-} DEMATEL

To show the procedure of calculating causal dependencies and local priorities among risk factors by IT2F-DEMATEL, the severity, probability of occurrence and probability of detection were primarily considered as potential candidates.

Step 1: The degrees of causal dependencies among factors are elicited by cross-functional experts, as shown in Appendix A.1 to A.5, where linguistic variables are used showing causal relationships among risk factors and are provided in Table 2.

Step 2: The average influence matrix is constructed by employing Eq. (18) and Eq. (19). The generated initial direct relation matrix is provided in Appendix B.1.

Step 3: The normalized initial direct relation matrix is obtained by using Eq. (20) - Eq. (23). In this case, the normalized coefficient is 1.433. This matrix is given in Appendix B.2. 
Table 1. Different failure modes of the components of the gearbox, their causes and effects

\begin{tabular}{|c|c|c|c|c|c|}
\hline Components & Notations & Failure Modes & Failure causes & \multicolumn{2}{|r|}{ Failure effects } \\
\hline \multirow{9}{*}{ Gear } & \multirow{3}{*}{ FM1 } & \multirow{3}{*}{ Wear of Teeth } & \multirow{3}{*}{$\begin{array}{l}\text { - Due to excessive load on } \\
\text { tooth profile. This load is } \\
\text { larger than the endurance } \\
\text { limit of the material, } \\
\text { - improper mounting of } \\
\text { gears, } \\
\text { - poor lubricating } \\
\text { condition, } \\
\text { - improper heat treatment } \\
\text { of gear material, } \\
\text {-impurities in the } \\
\text { lubricating oil. }\end{array}$} & Economical & $\begin{array}{l}\text { - Delay in timely delivery of the final product, } \\
\text { - Production of out-of-design final product, } \\
\text { - For excessive wear, other costs are incurred, like procurement } \\
\text { cost, ordering cost, lost production, etc. }\end{array}$ \\
\hline & & & & Social & $\begin{array}{l}\text { - Excessive wear leads to increased noise and vibration, } \\
\text { increase of smear by lubricant, which can harm the operators } \\
\text { physically, } \\
\text { - Lost production time is compensated with excess labour } \\
\text { hours to meet the output target, } \\
\text { - Worker's mind-set is changed due to repetitive failure and } \\
\text { interruption. }\end{array}$ \\
\hline & & & & Environmental & $\begin{array}{l}\text { - Produce harmful and toxic gases due to burning of lubricants, } \\
\text { - Proper disposal of burnt lubricating oil, waste material and } \\
\text { their recycling are a major problem. }\end{array}$ \\
\hline & & & & Economical & $\begin{array}{l}\text { Excessive lead time, out-of-design final product preparation, } \\
\text { and other procurement and installation related costs. }\end{array}$ \\
\hline & FM2 & Broken Teeth & $\begin{array}{l}\text { - fatigue breakage from } \\
\text { cyclic loading, } \\
\text { - excessive wear of teeth } \\
\text { and thinning of teeth, etc. }\end{array}$ & Social & $\begin{array}{l}\text { - Can obstruct the smooth movement of red-hot cast bloom } \\
\text { and subsequently those blooms can fall out of the pathway, } \\
\text { which will harm the operator, } \\
\text { - excess working hours for the operators, and change of their } \\
\text { mind-set, etc. }\end{array}$ \\
\hline & & & & Environmental & - Same as FM1. \\
\hline & & & $\begin{array}{l}\text { - Improper consideration } \\
\text { of hardness, texture and }\end{array}$ & Economical & -Same as FM1 and FM2 \\
\hline & FM3 & Pitting of Gear & $\begin{array}{l}\text { load. Actual born load } \\
\text { generally exceeds the }\end{array}$ & Social & -Same as FM1 and FM2 \\
\hline & & & $\begin{array}{l}\text { endurance limit, } \\
\text { - excessive hardening or } \\
\text { crispiness of gear surface, }\end{array}$ & Environmental & -Same as FM1 and FM2 \\
\hline
\end{tabular}




\begin{tabular}{|c|c|c|c|c|c|}
\hline & & & $\begin{array}{l}\text { - use of improper } \\
\text { lubricating oil, etc. }\end{array}$ & & \\
\hline & \multirow{3}{*}{ FM4 } & \multirow{3}{*}{$\begin{array}{l}\text { Axial Shift of } \\
\text { Gear }\end{array}$} & \multirow{3}{*}{$\begin{array}{l}\text { - Improper mounting due } \\
\text { to lack of knowledge of } \\
\text { the operator, } \\
\text { - sudden excessive load, } \\
\text {-improper design of teeth } \\
\text { profile, etc. }\end{array}$} & Economical & $\begin{array}{l}\text {-It can incur huge economic losses, in terms of lost } \\
\text { production, higher lead time, damage of final product, etc. }\end{array}$ \\
\hline & & & & Social & $\begin{array}{l}\text { - Can harm the operator physically and fatal accident may } \\
\text { occur. }\end{array}$ \\
\hline & & & & Environmental & $\begin{array}{l}\text { - Same as FM1, } \\
\text { - at the initial stage, more energies are required to move the } \\
\text { other meshing gears, etc. }\end{array}$ \\
\hline & \multirow{3}{*}{ FM5 } & \multirow{3}{*}{$\begin{array}{l}\text { Scoring of } \\
\text { gears }\end{array}$} & \multirow{3}{*}{$\begin{array}{l}\text { - poor quality of } \\
\text { lubricating oil, with } \\
\text { improper viscosity, } \\
\text { - poor matching of } \\
\text { material, } \\
\text {-improper cooling of } \\
\text { lubricating oils, larger } \\
\text { loads, etc. }\end{array}$} & Economical & - Same as FM1 \\
\hline & & & & Social & $\begin{array}{l}\text { - Scoring of gear can lead to other types of failures, like wear, } \\
\text { breakage of teeth or axial shifts and can cause similar types of } \\
\text { damages as mentioned above. }\end{array}$ \\
\hline & & & & Environmental & - Same as FM1 and FM4. \\
\hline \multirow{4}{*}{ Bearing } & \multirow{3}{*}{ FM6 } & \multirow{3}{*}{ Brinelling } & \multirow{3}{*}{$\begin{array}{l}\text { - shock or excessive loads } \\
\text { due to improper } \\
\text { mounting, } \\
\text { - excessive static or } \\
\text { impact load during } \\
\text { operation, } \\
\text { - improper installation } \\
\text { and handling, etc. }\end{array}$} & Economical & $\begin{array}{l}\text { - Can damage other components of the bearing which will } \\
\text { lead to total replacement, } \\
\text { - excessive vibration can damage the final dimension of the } \\
\text { cast blooms, etc. }\end{array}$ \\
\hline & & & & Social & $\begin{array}{l}\text { - At the later stage, due to excessive vibration, can lead to } \\
\text { fatal accident, } \\
\text { - replacement of bearing will cause increased lead-time, } \\
\text { affects the worker's mind-set to a great extent, etc. }\end{array}$ \\
\hline & & & & Environmental & $\begin{array}{l}\text { - Can damage the lubrication oil, which in turns damage the } \\
\text { other parts, and can produce some toxic gases at the burnt } \\
\text { condition, } \\
\text { - draw excessive energy for operation, etc. }\end{array}$ \\
\hline & FM7 & Cage defect & $\begin{array}{l}\text { - Excessive vibration } \\
\text { caused due to damage of } \\
\text { other components, }\end{array}$ & Economical & - Same as FM6 \\
\hline
\end{tabular}




\begin{tabular}{|c|c|c|c|c|c|}
\hline & & & $\begin{array}{l}\text { - contamination and } \\
\text { insufficiency of } \\
\text { lubricating oil, } \\
\text { - fluctuation in the }\end{array}$ & Social & - Same as FM6 \\
\hline & & & $\begin{array}{l}\text { rotating speed due to } \\
\text { shocks coming from cast } \\
\text { blooms, } \\
\text { - improper alignment of } \\
\text { balls, etc. }\end{array}$ & Environmental & - Same as FM6 \\
\hline & \multirow{3}{*}{ FM8 } & \multirow{3}{*}{$\begin{array}{l}\text { Crack on } \\
\text { raceways }\end{array}$} & \multirow{3}{*}{$\begin{array}{l}\text { - Excessive interference, } \\
\text { - excessive load and } \\
\text { shock load, } \\
\text { - flaking progression, } \\
\text { - generation of heat due to } \\
\text { creep, } \\
\text { - poor taper angle of } \\
\text { tapered shaft, etc. }\end{array}$} & Economical & - Same as FM6 \\
\hline & & & & Social & - Same as FM6 \\
\hline & & & & Environmental & - Same as FM6 \\
\hline & \multirow{3}{*}{ FM9 } & \multirow{3}{*}{$\begin{array}{l}\text { Crack of } \\
\text { rollers }\end{array}$} & \multirow{3}{*}{$\begin{array}{l}\text { - Almost similar causes } \\
\text { like FM8 }\end{array}$} & Economical & - Same as FM6 \\
\hline & & & & Social & - Same as FM6 \\
\hline & & & & Environmental & - Same as FM6 \\
\hline \multirow{5}{*}{ Shaft } & \multirow{3}{*}{ FM10 } & \multirow{3}{*}{ Bent shaft } & \multirow{3}{*}{$\begin{array}{l}\text { - Mostly due to improper } \\
\text { installation and setup } \\
\text { activities, } \\
\text { - heavy shock loads } \\
\text { during operation, } \\
\text { - thermal expansion or } \\
\text { contraction caused due to } \\
\text { other reasons, etc. }\end{array}$} & Economical & $\begin{array}{l}\text { - Can lead to replacement of the shaft, which will take severe } \\
\text { delay in production, huge monetary losses to the organization, } \\
\text { - affect the final dimension of the output product, etc. }\end{array}$ \\
\hline & & & & Social & $\begin{array}{l}\text { - can lead to fatal accidents of the operators, } \\
\text { - affects the working mentality of the operator, } \\
\text { - overtime work to meet the output target, etc. }\end{array}$ \\
\hline & & & & Environmental & $\begin{array}{l}\text { - Generates a lot of waste material which in turn creates a } \\
\text { proper disposal problem, } \\
\text { - creates excessive heat and burns the lubricating oil. Burnt } \\
\text { lubricating oil generates toxic gases, etc. }\end{array}$ \\
\hline & & & - metallurgical & Economical & - Similar to FM10 \\
\hline & FM11 & Crack of shaft & $\begin{array}{l}\text { abnormalities, } \\
\text { - cyclic fatigue, }\end{array}$ & Social & - Similar to FM10 \\
\hline
\end{tabular}




\begin{tabular}{|c|c|c|l|c|l|}
\hline & & $\begin{array}{l}\text { - excessive torque, } \\
\text { - increased stress due to } \\
\text { misalignment, etc. }\end{array}$ & Environmental & - Similar to FM10 \\
\cline { 2 - 5 } & FM12 & $\begin{array}{c}\text { Fracture of } \\
\text { shaft }\end{array}$ & $\begin{array}{l}\text { - Heavy loads, } \\
\text { - cyclical stress, } \\
\text { - poor design, etc. }\end{array}$ & Economical & - Similar to FM10 \\
\cline { 3 - 5 } & & Environmental & - Similar to FM10 \\
\hline
\end{tabular}

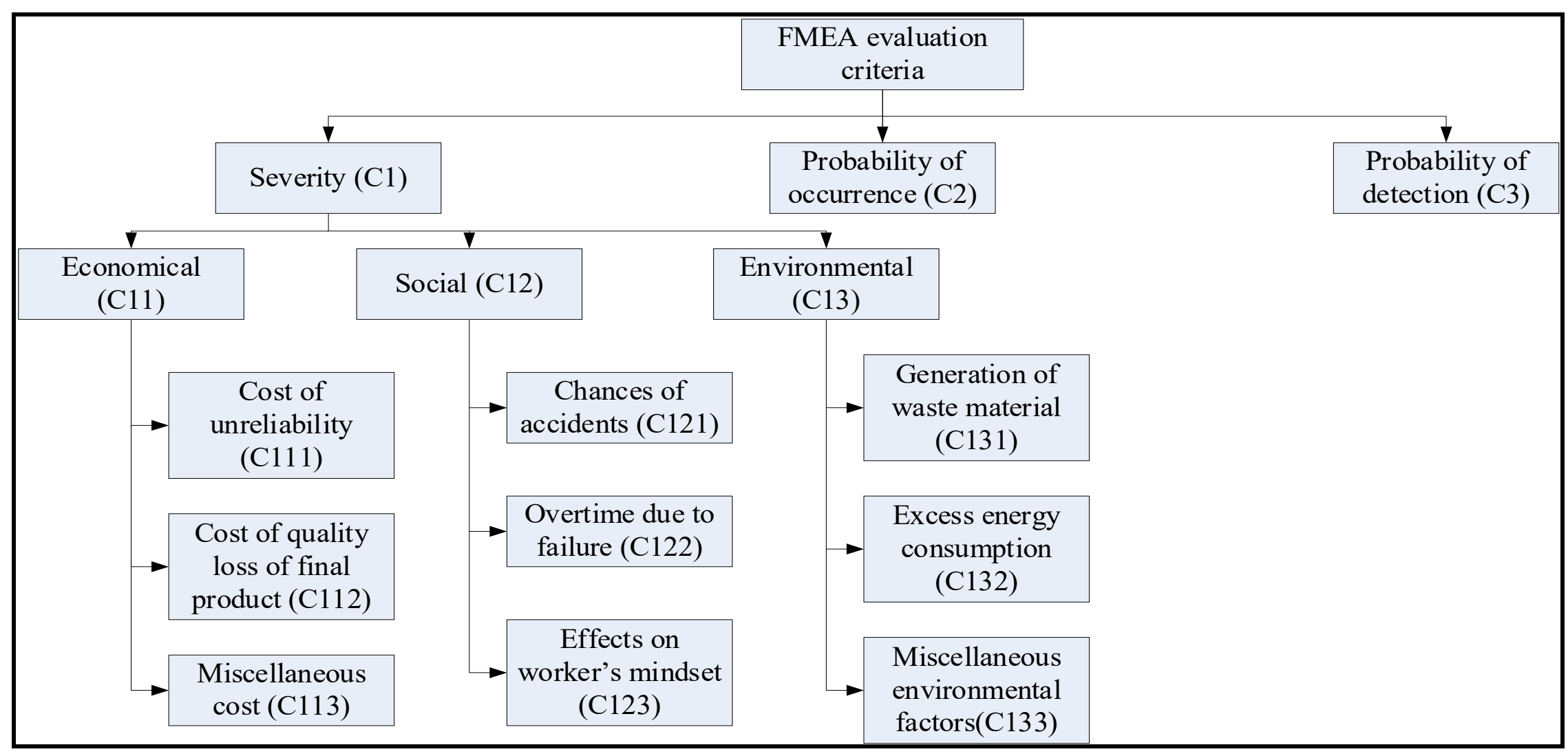

Figure 4. Factors considered for FMEA 
Table 2. Linguistic variables for causal relationships among attributes

\begin{tabular}{|c|c|}
\hline Linguistic variable & IT2FN \\
\hline Very-very low (VVL) & $((0,0.1,0.1,0.2 ; 1,1),(0.05,0.1,0.1,0.15 ; 0.9,0.9))$ \\
\hline Very low (VL) & $((0.1,0.2,0.2,0.35 ; 1,1),(0.15,0.2,0.2,0.3 ; 0.9,0.9))$ \\
\hline Low (L) & $((0.2,0.35,0.35,0.5 ; 1,1),(0.25,0.35,0.35,0.45 ; 0.9,0.9))$ \\
\hline Medium (M) & $((0.35,0.5,0.5,0.65 ; 1,1),(0.4,0.5,0.5,0.6 ; 0.9,0.9))$ \\
\hline High (H) & $((0.5,0.65,0.65,0.8 ; 1,1),(0.55,0.65,0.65,0.75 ; 0.9,0.9))$ \\
\hline Very high (VH) & $((0.65,0.8,0.8,0.9 ; 1,1),(0.7,0.8,0.8,0.85 ; 0.9,0.9))$ \\
\hline Very-very high $(\mathrm{VVH})$ & $((0.8,0.9,0.9,1 ; 1,1),(0.85,0.9,0.9,0.95 ; 0.9,0.9))$ \\
\hline
\end{tabular}

2 Step 4: Total relation matrix is provided in Appendix B.3 and is being calculated by using Eq. (24) 3 Eq. (26).

4 Step 5: Next, the structural correlation analysis is performed, by employing Eq. (27) and Eq. (28) .

5 Thus, $\tilde{\widetilde{R}}$ and $\widetilde{\widetilde{D}}$ values are obtained, respectively, as provided in Table 3.

Table 3. Sum of rows and columns of total relation matrix

\begin{tabular}{|c|c|c|}
\hline & $\widetilde{D}$ & $\tilde{R}$ \\
\hline $\mathbf{S}$ & $((1.0760,1.7811,1.7811,3.0022 ; 1.000,1.000)$, & $((0.9435,1.6393,1.6393,2.8626 ; 1.000 ; 1.000)$, \\
& $(1.290,1.781,1.781,2.419 ; 0.900,0.900))$ & $(1.150,1.639,1.639,2.295 ; 0.900,0.900))$ \\
\hline $\mathbf{O}$ & $((0.3138,0.6791,0.6791,1.3961 ; 1.000,1.000)$, & $((0.2938,0.6445,0.6445,1.34744 ; 1.000,1.000)$, \\
& $(0.426,0.679,0.679,1.073 ; 0.900,0.900))$ & $(0.400,0.644,0.644,1.034 ; 0.900,0.900))$ \\
\hline $\mathbf{D}$ & $((0.7966,1.3582,1.3582,2.3268 ; 1.000,1.000)$, & $((0.9492,1.5345,1.5345,2.5152 ; 1.000,1.000)$, \\
& $(0.959,1.358,1.358,1.868 ; 0.900,0.900))$ & $(1.125,1.535,1.535,2.031 ; 0.900,0.900))$ \\
\hline
\end{tabular}

7 Step 6: Further, the values of $E\left(\widetilde{\widetilde{D}}_{j} \oplus \tilde{\tilde{R}}_{j}\right)$ and $E\left(\widetilde{\widetilde{D}}_{j} \ominus \tilde{\widetilde{R}}_{j}\right)$ are computed by using Eq. (17). The local priorities are calculated by using Eq. (29) - Eq. (30) and are presented in Table 4-Table 5, respectively.

Table 4. $\widetilde{\widetilde{D}} \oplus \tilde{\tilde{R}}$ values

\begin{tabular}{|c|c|c|}
\hline & $\widetilde{\widetilde{D}} \oplus \tilde{\tilde{R}}$ & $\widetilde{\widetilde{D}} \Theta \tilde{\tilde{R}}$ \\
\hline $\mathbf{S}$ & $((2.0195,3.4204,3.4204,5.8647 ; 1.000,1.000)$, & $((-1.7865,0.1417,0.1417,2.0587 ; 1.000,1.000)$, \\
& $(2.4402,3.4204,3.4204,4.7136 ; 0.900,0.900))$ & $(-1.005,0.142,0.142,1.269 ; 0.900,0.900))$ \\
\hline $\mathbf{O}$ & $((0.6076,1.3236,1.3236,2.7435 ; 1.000,1.000)$, & $((-1.0336,0.0346,0.0346,1.1023 ; 1.000,1.000)$, \\
& $(0.8261,1.3236,1.3236,2.1078 ; 0.900,0.900))$ & $(-0.608,0.035,0.035,0.673 ; 0.900,0.900))$ \\
\hline $\mathbf{D}$ & $((1.7458,2.8927,2.8927,4.8420 ; 1.000,1.000)$, & $((-1.7185,-0.1763,-0.1763,1.3777 ; 1.000,1.000)$, \\
& $(2.0837,2.8927,2.8927,3.8989 ; 0.900,0.900))$ & $(-1.072,-0.176,-0.176,0.743 ; 0.900,0.900))$ \\
\hline
\end{tabular}

Table 5. Final weights of S-O-D factors

\begin{tabular}{|c|c|c|c|c|}
\hline & D+R & D-R & Weights & $\begin{array}{c}\text { Normalized } \\
\text { weight }\end{array}$ \\
\hline S & 3.231 & 0.13095 & 3.234 & 0.446 \\
\hline $\mathbf{O}$ & 1.303 & 0.032303 & 1.303 & 0.180 \\
\hline $\mathbf{D}$ & 2.716 & -0.16325 & 2.721 & 0.375 \\
\hline
\end{tabular}


In a similar way, the relative importance of the sub-factors is computed. Finally, we calculate

2 the overall weights of all the considered factors, as presented in Table 6, as subsequently utilized in the

3 next step of ranking the failure modes.

Table 6. Calculated weights of considered factors by IT2FS-DEMATEL

\begin{tabular}{|c|c|c|c|c|c|c|}
\hline Factors & Weights & Sub factors & $\begin{array}{c}\text { Sub- } \\
\text { factor } \\
\text { weights }\end{array}$ & $\begin{array}{c}\text { Sub-sub } \\
\text { factors }\end{array}$ & $\begin{array}{l}\text { Sub-sub } \\
\text { factor } \\
\text { weights }\end{array}$ & $\begin{array}{l}\text { Overall } \\
\text { weights }\end{array}$ \\
\hline \multirow[t]{9}{*}{ Severity } & \multirow[t]{9}{*}{0.446} & \multirow[t]{3}{*}{ Economical } & \multirow[t]{3}{*}{0.361} & $\begin{array}{c}\text { Cost of } \\
\text { unreliability }\end{array}$ & 0.436 & 0.070 \\
\hline & & & & $\begin{array}{c}\text { Cost of quality } \\
\text { loss }\end{array}$ & 0.261 & 0.041 \\
\hline & & & & $\begin{array}{c}\text { Miscellaneous } \\
\text { cost }\end{array}$ & 0.303 & 0.049 \\
\hline & & \multirow[t]{3}{*}{ Social } & \multirow[t]{3}{*}{0.324} & $\begin{array}{l}\text { Chances of } \\
\text { accidents }\end{array}$ & 0.302 & 0.044 \\
\hline & & & & $\begin{array}{l}\text { Overtime due } \\
\text { to failure }\end{array}$ & 0.304 & 0.044 \\
\hline & & & & $\begin{array}{c}\text { Effects on } \\
\text { workers mind- } \\
\text { set }\end{array}$ & 0.394 & 0.057 \\
\hline & & \multirow[t]{3}{*}{ Environmental } & \multirow[t]{3}{*}{0.315} & $\begin{array}{c}\text { Generation of } \\
\text { waste material }\end{array}$ & 0.389 & 0.055 \\
\hline & & & & $\begin{array}{l}\text { Excess energy } \\
\text { consumption }\end{array}$ & 0.313 & 0.044 \\
\hline & & & & $\begin{array}{l}\text { Miscellaneous } \\
\text { environmental } \\
\text { factors }\end{array}$ & 0.298 & 0.042 \\
\hline $\begin{array}{l}\text { Probability } \\
\text { of } \\
\text { occurrence }\end{array}$ & 0.180 & ---- & --- & ---- & ---- & 0.180 \\
\hline $\begin{array}{l}\text { Probability } \\
\text { of detection }\end{array}$ & 0.375 & ---- & ---- & $\begin{array}{ll}--- \\
\end{array}$ & ---- & 0.375 \\
\hline
\end{tabular}

Severity-Occurrence-Detection

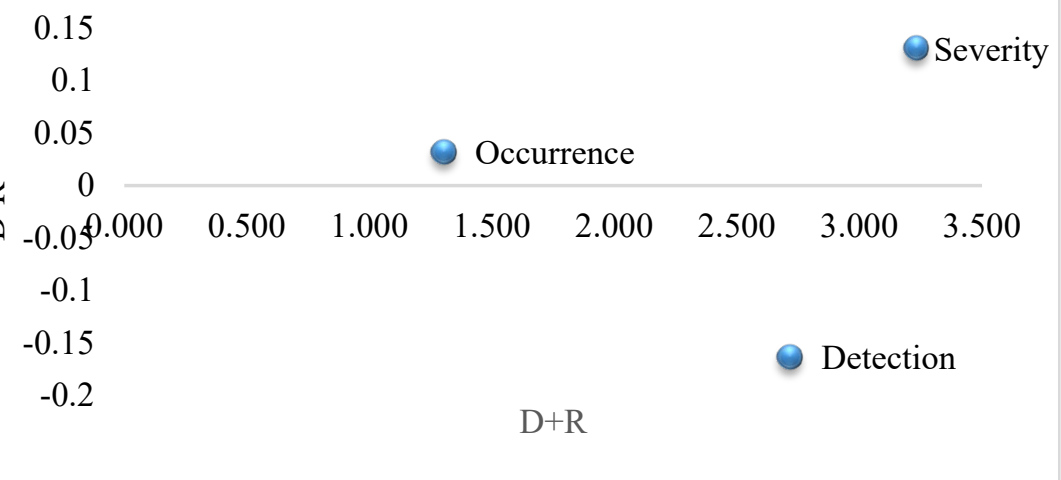

Figure 5. Causal diagram of Severity-Occurrence-Detection

7 The causal diagram between severity $(\mathrm{C} 1)$, occurrence $(\mathrm{C} 2)$ and detection $(\mathrm{C} 3)$ is represented 8 by Figure 5. The cause group is known as the influencing factors and the effect group is known as the 
1 influenced factors. From the results, it is recommended to the decision makers that they must give their

2 attention to the cause group, which subsequently controls the effect group. In this case study, decision

3 makers are advised to give their utmost priority to the severity $(\mathrm{C} 1)$ and occurrence $(\mathrm{C} 2)$ factors.

4 Referring to Figure 5, severity (C1) is decoupled into several sustainable indices, economical (C11),

5 societal (C12) and environmental (C13) sub-factors, which should be considered for further

6 improvement of the system. On the other side, chances of occurrence (C2) can only be decreased if

7 proper maintenance procedures are followed. It is also necessary that the plant is equipped with,

8 wherever feasible, technologically advanced modern fault detection instrumentation with automated

9 fault diagnosis arrangements. Further, it is observed from Table 5 that severity $(\mathrm{C} 1)$ has the highest

10 prominence value (3.231) and relation value (0.1309). It implies that severity (C1) is the most influencing factor above the other two factors. Whereas, a high relation value implies that it is not influenced by other factors and sub-factors. Hence, in this situation, it is always preferable to give attention to improve other factors for overall system improvement. The only member in the effect group is detection (C3), whose $(D-R)$ value is quite low (-0.1632). This implies that chances of improvement with this factor are the highest.

Similarly, the causal dependencies among other RFs under severity $(\mathrm{C} 1)$ are computed and shown in Figure 6 to Figure 9. Like previous analysis, $\mathrm{C} 1$ is decoupled and as it also belongs to the cause group (or influencing factor), it is necessary to analyse it further. From Figure 6, it is observed that the economical aspect $(\mathrm{C} 11)$ has the highest prominence value (5.388), but a lower relation value $(-0.1607)$. Furthermore, it belongs to the effect group along with the social aspects (C12), which is influenced by the environmental aspects (C13), whose prominence value (4.654) is lower that the economic aspects but has the highest relation value (0.6359). In such a scenario, the advice is to give the utmost importance to environmental aspects (C13), as it is the strongest influencing one.

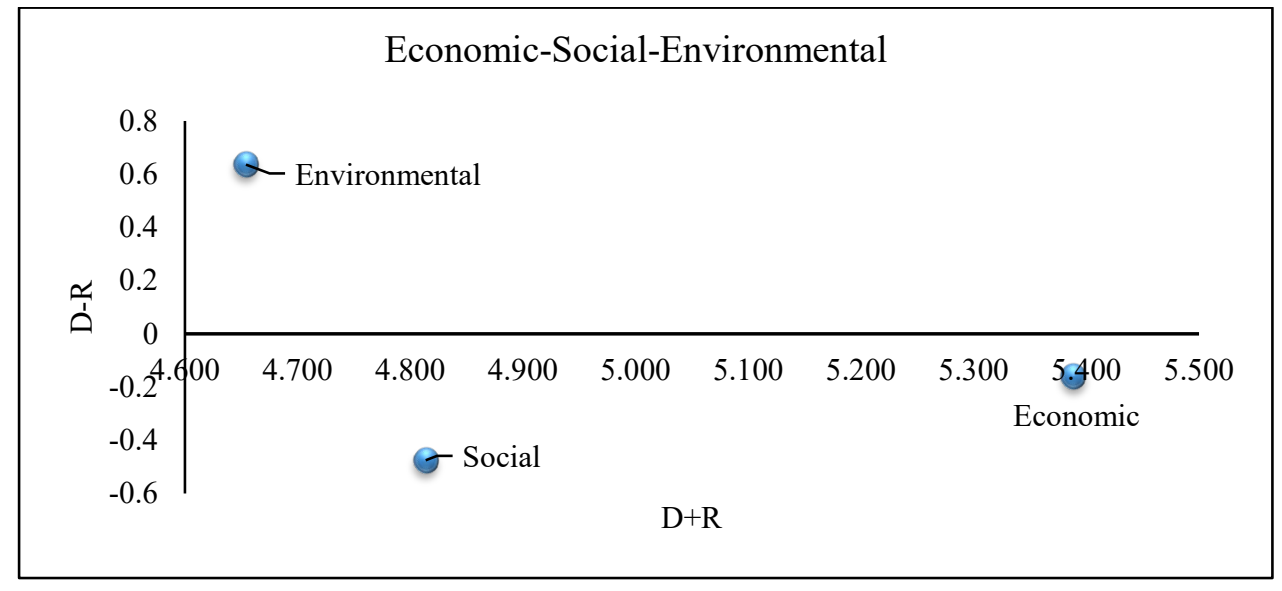

Figure 6. Causal diagram of Economic-Social-Environmental criteria

As environmental aspects belong to the cause group, it is further analysed for better inferences. From Figure 7, it is observed that generation of waste material (C131) has the highest prominence value (3.330) and lower relation value (0.3367). It also belongs to the cause group along with excess energy 
1 consumption (C132), which has less prominence value (2.674) and highest relation value (0.3557).

2 These imply that generation of waste material (C131) is the most worrying sub-factor rather than excess

3 energy consumption (C132), when the severity is considered from an environmental point of view.

4 Other miscellaneous environmental factors (C133) include generation of toxic gases, fumes, dusts, etc.

5 when the gearbox is operated in degraded conditions.

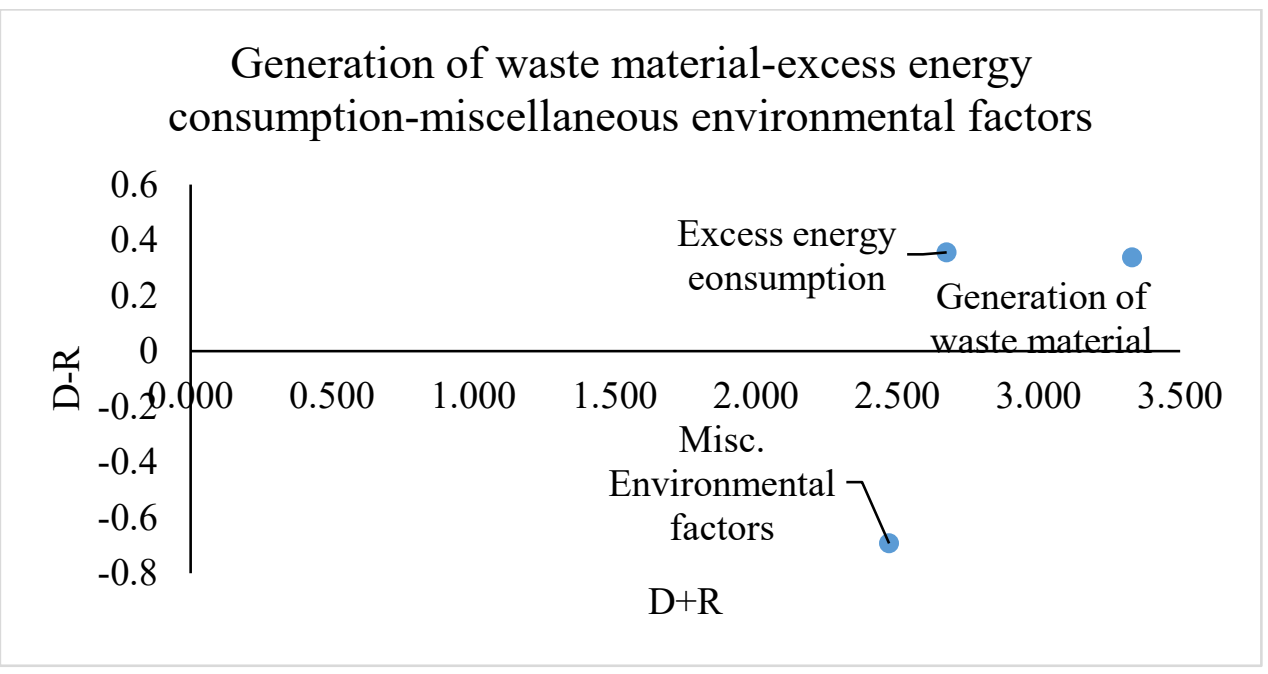

7 Figure 7. Causal diagram of Generation of waste material-excess energy consumption-miscellaneous environmental factors

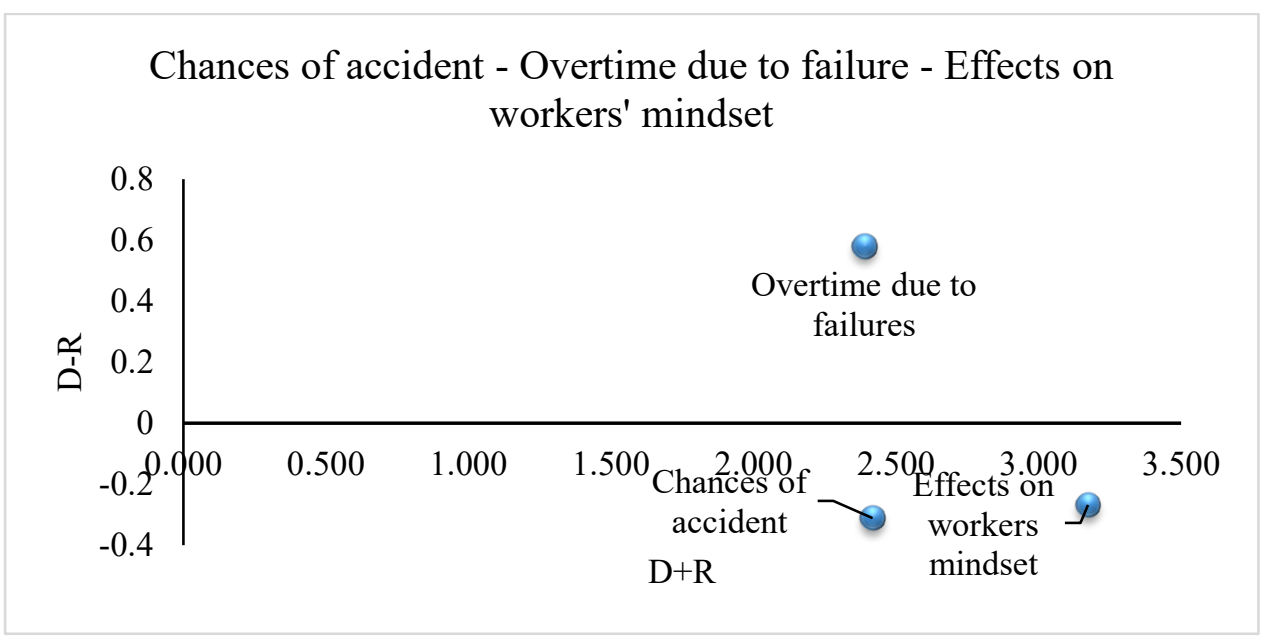

Figure 8. Causal diagram of Chances of accident - Overtime due to failure - Effects on workers' mind-set

From Figure 8, from the societal point of view, it is observed that effects on workers' mindset due to failure (C123) has the largest prominence value (3.173) with largest local priority (0.394), although it belongs to the effect group. It is due to that fact that each worker is normally given set task(s) during their working hours. However, when a gearbox encounters a catastrophic failure, their mind-set and efficiency changes. Overtime due to failure (C122) belongs to the cause group, as it influences the chances of accidents due to improper vigilance and machinery failure. Chances of accidents has the 
1 least relation value (-0.3112) and implies that it can be further improved by preventing failure of the 2 machinery.

3
Cost of unrelaibility- Cost of quality loss-Miscellaneous cost

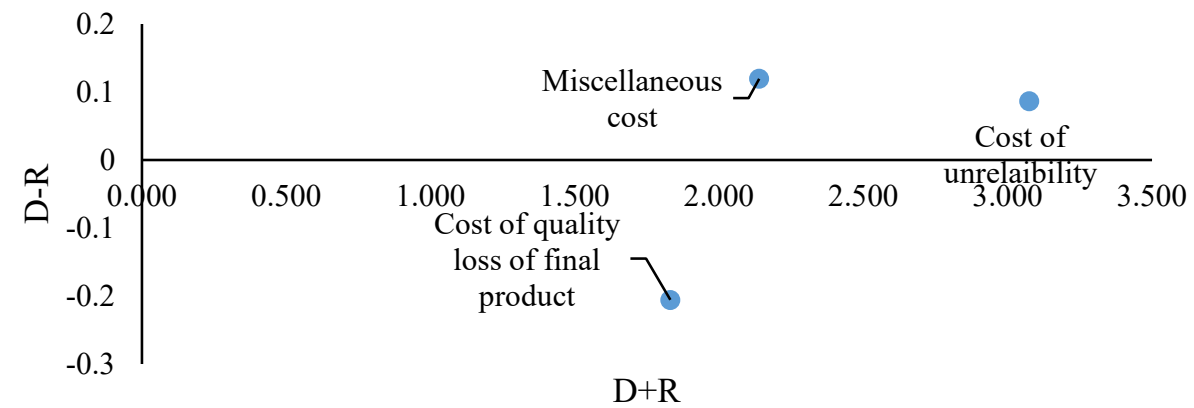

$\mathrm{D}+\mathrm{R}$

Figure 9. Causal diagram of cost of unreliability-cost of quality loss of final product-miscellaneous cost

From an economical point of view, cost of unreliability (C111) and miscellaneous cost (C113) belongs to the cause group and have local priorities of $43.6 \%$ and $30.3 \%$, respectively, as shown in Figure 9. Cost of unreliability (C111) is increased with number of failures, which can be controlled if the detection level is high enough and complemented by proactive maintenance efforts. Miscellaneous cost includes several factors such as inventory costs, procurement costs, etc. whose data are not easy to get, hence they are depicted linguistically. The only factor that belongs to the effect group is cost of quality loss of final product $(\mathrm{C} 112)$, whose $(D-R)$ value is least $(-0.2056)$ and can only be improved if the other two indices, $\mathrm{C} 11$ and $\mathrm{C} 113$ are improved.

After calculating relative importance and causal dependencies of all factors and sub-factors, the next step is to rank the failure modes according to their level of risks.

\subsection{Ranking of failure modes}

The following steps are involved in risk-ranking of failure modes:

Step 1: Linguistic decision matrices are obtained from cross-functional experts placed in Appendix C. Using Table 7, the initial decision matrix is obtained. 
Table 7. Fuzzy evaluation scores for alternatives

\begin{tabular}{|c|c|}
\hline Linguistic terms & Fuzzy score \\
\hline Very Poor (VP) & $(0,0,1)$ \\
\hline Poor (P) & $(0,1,3)$ \\
\hline Medium Poor (MP) & $(1,3,5)$ \\
\hline Fair (F) & $(3,5,7)$ \\
\hline Medium Good (MG) & $(5,7,9)$ \\
\hline Good (G) & $(7,9,10)$ \\
\hline Very Good (VG) & $(9,10,10)$ \\
\hline
\end{tabular}

2 Step 2: Using Eq. (32), the aggregated decision matrix is obtained.

3 Step 3: Next, the initial decision matrix is normalized by using Eq. (33)-(34) as given in Table 8.

4

Table 8. Fuzzy normalized decision matrix

\begin{tabular}{|c|c|c|c|c|c|}
\hline Failure Modes & C111 & C112 & C113 & C121 & $\mathrm{C122}$ \\
\hline Wear of Teeth & $(0.117,0.159,0.193)$ & $(0.019,0.067,0.125)$ & $(0,0.021,0.075)$ & $(0,0.025,0.088)$ & $(0.053,0.117,0.181)$ \\
\hline Broken Teeth & $(0.159,0.193,0.207)$ & $(0.01,0.048,0.106)$ & $(0.011,0.053,0.118)$ & $(0.013,0.063,0.139)$ & $(0.245,0.299,0.32)$ \\
\hline Pitting & $(0.062,0.104,0.145)$ & $(0.01,0.038,0.087)$ & $(0.043,0.096,0.16)$ & $(0.013,0.063,0.139)$ & $(0.181,0.245,0.299)$ \\
\hline Axia & $(0.173$, & $(0.106,0.1$ & $(0.043,0$. & $(0.088,0$. & .139) \\
\hline Scor & $(0.007, \mathrm{C}$ & $(0.01$ & $(0.01)$ & $(0.013$ & $7,0.309)$ \\
\hline Brinelling & $(0.076,0.117,0.159)$ & $(0.048,0.106,0.164)$ & $(0,0.032,0$ & $(0.013,0.063,0.139)$ & $(0.139,0.203,0.267)$ \\
\hline Cage & $(0.159,0.193,0.207)$ & $(0.106,0.164,0.221)$ & $(0.246,0.299,0.321)$ & $(0.05,0.113,0.189)$ & $(0.064,0.117,0.181)$ \\
\hline Cracl & $(0.173,0.2,0.207)$ & $(0.106,0.164,0.221)$ & $(0.182,0.246,0.289)$ & $(0.013,0.0$ & $\overline{53,0.117)}$ \\
\hline Crack of & $(0.159,0$ & $(0.144,0$ & $(0.139,0.203$ & $(0.013,0$ & $0.139)$ \\
\hline Bent s & $(0.131,0.173,0.2)$ & $(0.183,0.241,0.279)$ & $(0.053,0.118,0.182)$ & $(0.164,0.239,0.315)$ & $(0.011,0.053,0.117)$ \\
\hline Crack of shaft & $(0.145,0.18,0.2)$ & $(0.164,0.221,0.26)$ & $(0.246,0.299,0.321)$ & $(0.139,0.214,0.29)$ & $(0.021,0.075,0.139)$ \\
\hline Fracture of shaft & $(0.173,0.2,0.207)$ & $(0.221,0.269,0.289)$ & $(0.011,0.053,0.118)$ & $(0.315,0.365$ & $(0.011,0.053,0.117)$ \\
\hline C123 & $\mathbf{C}$ & $\mathrm{C1}$ & $\mathbf{C}$ & C2 & $\mathrm{C}$ \\
\hline$(0.173,0.228,0.264)$ & $(0.086,0.144,0.201)$ & $(0.033,0.074,0.123)$ & $(0.043,0.1,0.186)$ & $(0.048,0.109,0.182)$ & $(0.097,0.141,0.186)$ \\
\hline$(0.155,0.209,0.255)$ & $(0.105,0.163,0.22)$ & $(0.057,0.107,0.156)$ & $(0.014,0.071,0.157)$ & $(0.061,0.133,0.206)$ & $(0.171,0.208,0.223)$ \\
\hline$(0.191,0.246,0.273)$ & $(0.038,0.086,0.144)$ & $(0.016,0.057,0.107)$ & $(0.014,0.071,0.157)$ & $(0.085,0.157,0.23)$ & $(0.141,0.186,0.216)$ \\
\hline$(0.1,0.155,0.209)$ & $(0,0.019,0.067)$ & $(0.139,0.189,0.2$ & $(0.043,0.1,0.186)$ & $(0.048,0.109,0.182)$ & $(0.037,0.082,0.126)$ \\
\hline$(0.173,0.228,0.264)$ & $(0.029,0.067,0.124)$ & $(0.008,0.041,0.09)$ & $(0.029,0.1,0.186)$ & $(0.061,0.133,0.206)$ & $(0.082,0.126,0.171)$ \\
\hline$(0.137,0.191,0.237)$ & $(0.057,0.105,0.163)$ & $(0.008,0.041,0.09)$ & $(0.057,0.129,0.214)$ & $(0.157,0.23,0.303)$ & $(0.037,0.082,0.126)$ \\
\hline$(0.009,0.046,0.1)$ & $(0.239,0.277,0.287)$ & $(0.123,0.172,0.213)$ & $(0.086,0.157,0.243)$ & $(0.012,0.061,0.133)$ & $(0.186,0.216,0.223)$ \\
\hline$(0.046,0.1,0.155)$ & $(0.019,0.067,0.124)$ & $(0.156,0.205,0.238)$ & $(0.014,0.071,0.157)$ & $(0.278,0.339,0.363)$ & $(0.201,0.223,0.223)$ \\
\hline$(0.009,0.046,0.1)$ & $(0.239,0.277,0.287)$ & $(0.172,0.222,0.246)$ & $(0.086,0.157,0.243)$ & $(0.085,0.157,0.23)$ & $(0.156,0.193,0.216)$ \\
\hline$(0,0.018,0.064)$ & $(0.057,0.105,0.163)$ & $(0.189,0.23,0.246)$ & $(0.086,0.157,0.243)$ & $(0.061,0.133,0.206)$ & $(0.082,0.126,0.171)$ \\
\hline$(0.082,0.137,0.191)$ & $(0.067,0.124,0.182)$ & $(0.172,0.222,0.246)$ & $(0.1,0.186,0.271)$ & $(0.012,0.061,0.133)$ & $(0.082,0.126,0.171)$ \\
\hline$(0.1,0.155,0.209)$ & $(0.22,0.268,0.287)$ & $(0.205,0.238,0.246)$ & $(0.243,0.328,0.386)$ & $(0,0.024,0.085)$ & $(0.186,0.216,0.223)$ \\
\hline
\end{tabular}

5 Step 4: Next, using Eq. (35), the matrix of preference according to the available alternatives is obtained.

6 In this case-study, the value is $\left(\frac{1}{m}\right)=0.0833$. 
1 Step 5: Matrix of theoretical ponder is obtained by using Eq. (36).

2 Step 6: Next, the matrix of actual ponder is calculated according to Eq.(37).

3 Step 7: The total gap matrix is calculated by using Eq. (38) as provided in Table 9.

4

Table 9. Total gap matrix

\begin{tabular}{|c|c|c|c|c|c|c|c|c|c|c|c|}
\hline $\begin{array}{c}\text { Failure } \\
\text { Modes }\end{array}$ & $\mathbf{C 1 1 1}$ & $\mathbf{C 1 1 2}$ & $\mathbf{C 1 1 3}$ & $\mathbf{C 1 2 1}$ & $\mathbf{C 1 2 2}$ & $\mathbf{C 1 2 3}$ & $\mathbf{C 1 3 1}$ & $\mathbf{C 1 3 2}$ & $\mathbf{C 1 3 3}$ & $\mathbf{C 2}$ & $\mathbf{C 3}$ \\
\hline $\begin{array}{c}\text { Wear of } \\
\text { Teeth }\end{array}$ & 0.0049 & 0.0032 & 0.0040 & 0.0035 & 0.0032 & 0.0037 & 0.0039 & 0.0034 & 0.0031 & 0.0133 & 0.0269 \\
\hline $\begin{array}{c}\text { Broken } \\
\text { Teeth }\end{array}$ & 0.0047 & 0.0032 & 0.0038 & 0.0034 & 0.0026 & 0.0038 & 0.0038 & 0.0033 & 0.0032 & 0.0130 & 0.0250 \\
\hline $\begin{array}{c}\text { Pitting of } \\
\text { Gear }\end{array}$ & 0.0052 & 0.0033 & 0.0037 & 0.0034 & 0.0028 & 0.0036 & 0.0042 & 0.0034 & 0.0032 & 0.0127 & 0.0256 \\
\hline $\begin{array}{c}\text { Axial Shift } \\
\text { of Gear }\end{array}$ & 0.0047 & 0.0029 & 0.0037 & 0.0031 & 0.0034 & 0.0040 & 0.0045 & 0.0030 & 0.0031 & 0.0133 & 0.0287 \\
\hline $\begin{array}{c}\text { Scoring of } \\
\text { gears }\end{array}$ & 0.0056 & 0.0032 & 0.0038 & 0.0034 & 0.0027 & 0.0037 & 0.0043 & 0.0035 & 0.0031 & 0.0130 & 0.0273 \\
\hline $\begin{array}{c}\text { Brinelling } \\
\text { Cage } \\
\text { defect }\end{array}$ & 0.0052 & 0.0031 & 0.0039 & 0.0034 & 0.0029 & 0.0039 & 0.0041 & 0.0035 & 0.0030 & 0.0116 & 0.0287 \\
\hline $\begin{array}{c}\text { Crack on } \\
\text { raceways }\end{array}$ & 0.0047 & 0.0029 & 0.0031 & 0.0034 & 0.0034 & 0.0043 & 0.0043 & 0.0029 & 0.0032 & 0.0101 & 0.0245 \\
\hline $\begin{array}{c}\text { Crack of } \\
\text { rollers }\end{array}$ & 0.0047 & 0.0027 & 0.0033 & 0.0034 & 0.0034 & 0.0045 & 0.0034 & 0.0029 & 0.0029 & 0.0127 & 0.0254 \\
\hline Bent shaft & 0.0049 & 0.0026 & 0.0036 & 0.0028 & 0.0034 & 0.0046 & 0.0041 & 0.0029 & 0.0029 & 0.0130 & 0.0273 \\
\hline $\begin{array}{c}\text { Crack of } \\
\text { shaft }\end{array}$ & 0.0048 & 0.0027 & 0.0029 & 0.0029 & 0.0034 & 0.0041 & 0.0040 & 0.0029 & 0.0029 & 0.0140 & 0.0273 \\
\hline $\begin{array}{c}\text { Fracture } \\
\text { of shaft }\end{array}$ & 0.0047 & 0.0025 & 0.0038 & 0.0024 & 0.0034 & 0.0040 & 0.0034 & 0.0028 & 0.0024 & 0.0145 & 0.0248 \\
\hline
\end{tabular}

5 Step 8: Table 10 shows the criteria function values as given in Eq. (39). As stated earlier, the failure

6 mode with the highest gap value is the worst one and vice-versa as per the proposed modified

7 FMAIRCA method.

Table 10. Defuzzied gap values and ranking of failure modes

\begin{tabular}{|c|c|c|}
\hline Failure Modes & $\begin{array}{c}\text { Criteria function } \\
\text { values }\end{array}$ & $\begin{array}{c}\text { Ranking of failure } \\
\text { modes by proposed } \\
\text { hybrid approach }\end{array}$ \\
\hline Wear of Teeth & 0.0732 & 10 \\
\hline Broken Teeth & 0.0700 & 5 \\
\hline Pitting of Gear & 0.0711 & 6 \\
\hline Axial Shift of Gear & 0.0744 & 12 \\
\hline Scoring of gears & 0.0738 & 11 \\
\hline Brinelling & 0.0733 & 4 \\
\hline Cage defect & 0.0696 & 3 \\
\hline Crack on raceways & 0.0669 & 8 \\
\hline Crack of rollers & 0.0693 & 7 \\
\hline Bent shaft & 0.0722 & 2 \\
\hline Crack of shaft & 0.0719 & \\
\hline Fracture of shaft & 0.0688 & \\
\hline
\end{tabular}




\section{Validation and discussions of the result}

In this section, the obtained risk-ranking of failure modes are validated. It is divided into two parts. In the first part, the obtained ranking result is compared with the fuzzy extensions of different MCDM methods, available in the FMEA literature. Secondly, a sensitivity analysis is carried out by varying the criteria weights to different levels and observing subsequent variations in failure mode rankings.

\subsection{Comparison of failure modes ranking with other MCDM methods}

In the FMEA domain, to arrive at a consensus about the ranking of failure modes as per their risk levels, it is often preferred to compare the result with other established methods. From the very recent review article of Liu et al. [16], it is observed that the most frequently used fuzzy MCDM methods in the FMEA domain are fuzzy extensions of TOPSIS, VIKOR, COPRAS, MOORA, and MABAC. Thus, the ranking result obtained in this work is compared with them. Along with that, the obtained result is also compared with the fuzzy extension of the MAIRCA method proposed by [19]. A comparative presentation of the failure modes ranking is presented in Figure 10.

\section{Comparison of result with other MCDM methods}

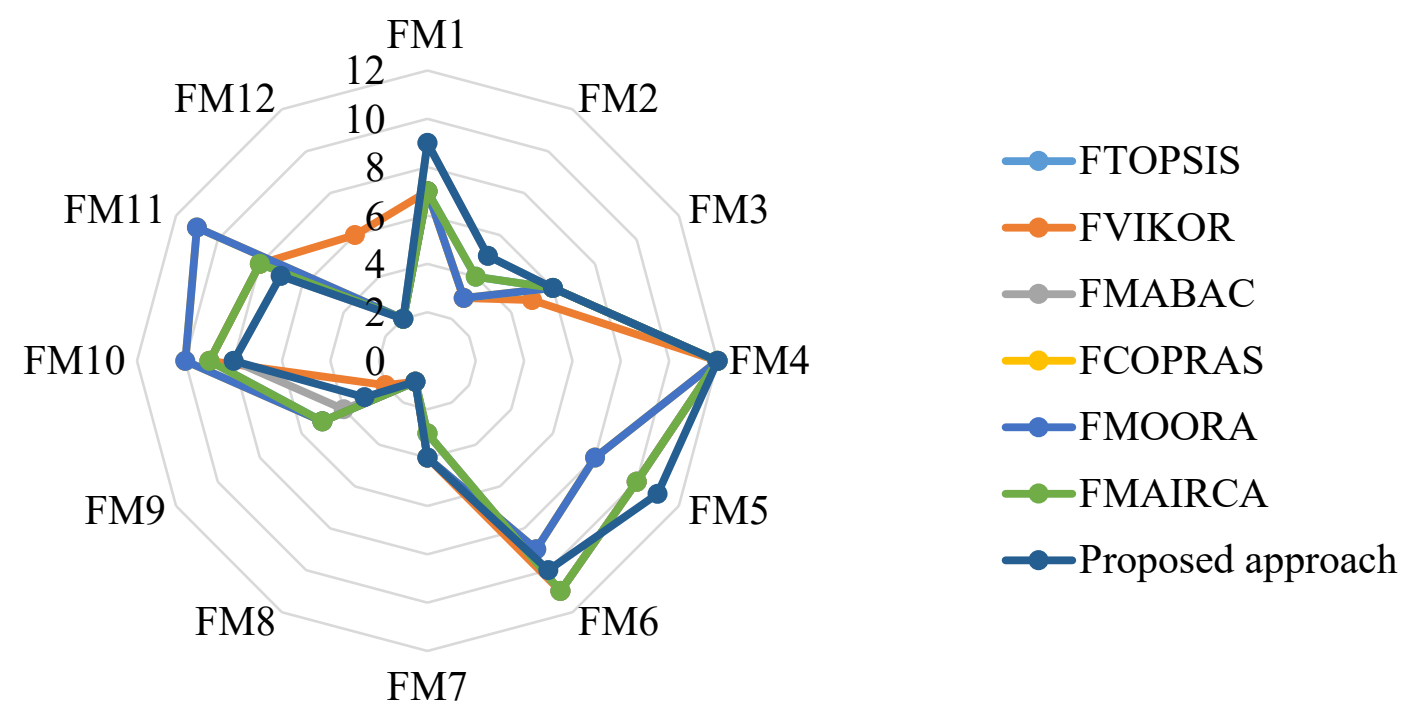

Figure 10. Failure modes ranking by different MCDM approaches

From the risk ranking of failure modes by using the fuzzy extensions of the previously mentioned MCDM methods, it is observed that each time, cracks on raceways (FM8) is identified as the most critical failure mode. Further, it is observed that the fracture of the shaft (FM12) is identified as the second critical failure mode by all other fuzzy MCDM methods, except FVIKOR [56], where it is ranked as the sixth critical failure mode. This is probably due to choosing the value of $v(0.5$ in our case), which is known as the weight for the strategy of maximum group utility, whereas $(1-v)$ is the weight of the individual regret. 
Prior to making a final decision, it is necessary to check the reliability of the ranking result, which

2 is generally measured by using Spearman's rank correlation coefficient. From Table 11, it is observed

3 that all the rank correlation coefficients are higher than 0.80 , with a mean value of 0.91 , which implies

4 that strong correlations are present between the proposed approach and other established MCDM

5 approaches [57]. Therefore, it is concluded that the proposed risk-ranking of failure modes are credible

6 and confirmed.

Table 9. Rank correlation among MCDM methods

\begin{tabular}{|c|c|c|c|c|c|c|c|}
\hline & FTOPSIS & FVIKOR & FMABAC & FCOPRAS & FMOORA & FMAIRCA & Average \\
\hline $\begin{array}{c}\text { Spearman's } \\
\text { rank } \\
\text { correlation } \\
\text { coefficient }\end{array}$ & 0.9510 & 0.8951 & 0.9860 & 0.8531 & 0.8531 & 0.9510 & 0.9148 \\
\hline
\end{tabular}

8

9

\subsection{Sensitivity analysis}

During FMEA, it is often required to change evaluations of criteria and alternatives. When the evaluations of criteria are changed, relative importance of risk factors are also changed. These changes affect the ranking results of failure modes. Therefore, it is necessary to observe the sensitivity of the model used to rank the failure modes, as well as to identify the important criteria which mainly cause the changes to failure mode rankings.

In this section, a total of 44 scenarios are considered for sensitivity analysis, which can be divided into four phases, where each phase is comprised of 11 scenarios. For each scenario, the relative importance of a single criterion was increased to different levels (in this case $20 \%, 40 \%, 60 \%$, and $80 \%$ ), while the other criteria were decreased by the same level. Further, the normalization procedure was performed to maintain the condition, $\sum_{i=1}^{n} w_{i}=1$. Variations in failure mode rankings for different levels of variation for each criterion are shown in Figure 11. After further verifications, it is observed from Table 12 that the proposed approach provides consistent rankings for most of the critical failure modes in each of the considered four phases. As TOPSIS is the mostly commonly applied MCDM method in the FMEA domain, result obtained by our proposed approach is compared with the fuzzy extension of TOPSIS. 


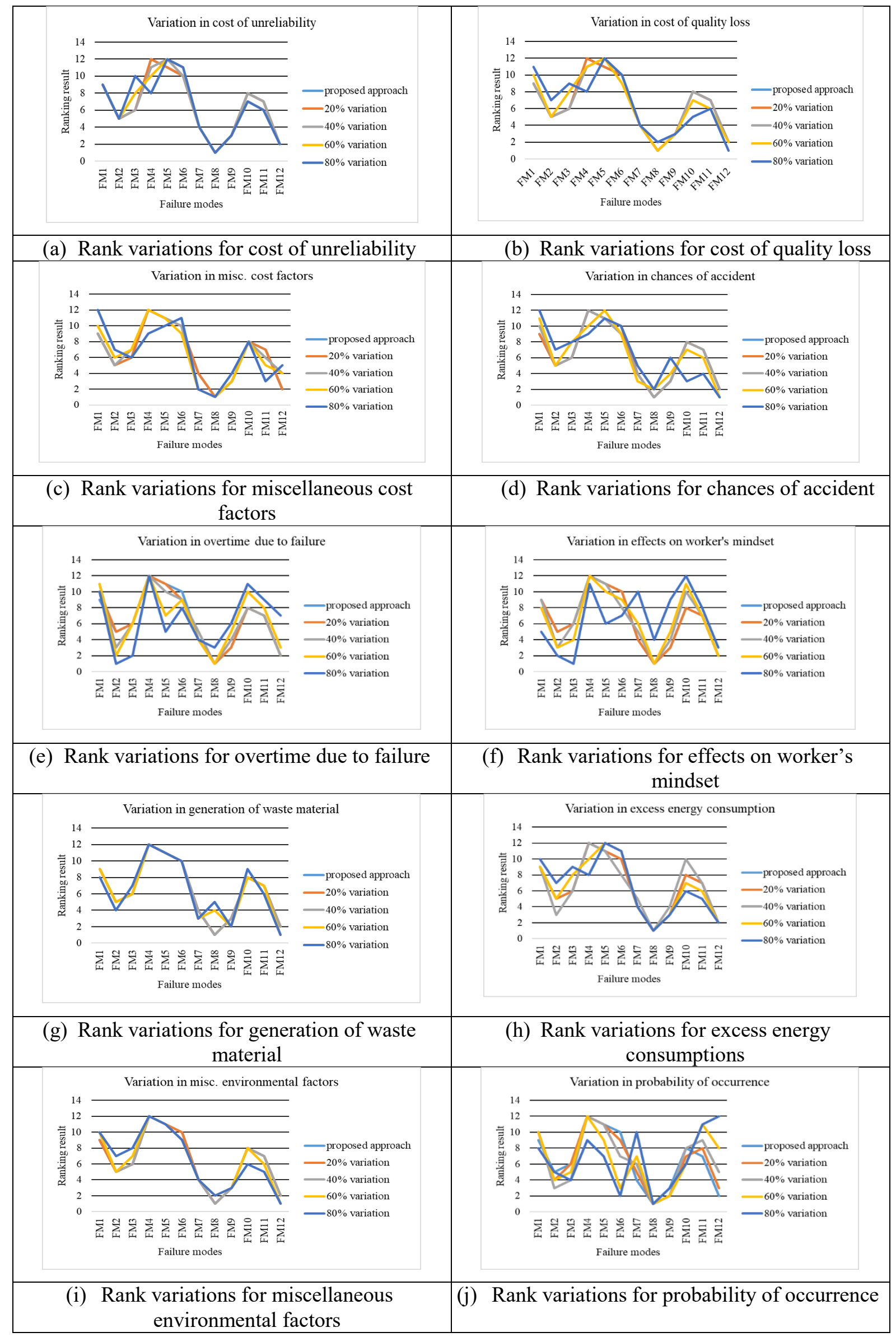




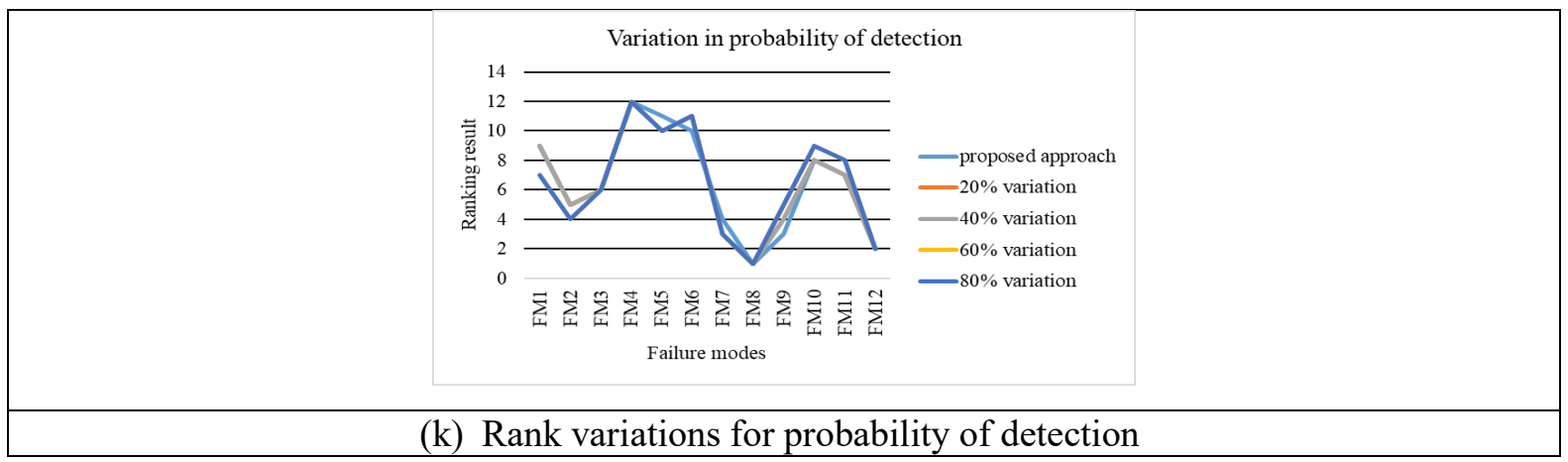

Figure 11. Variations of criteria weights and their effects on failure modes rankings

Table 12. Consistency in ranking result

\begin{tabular}{|c|c|c|c|}
\hline Ranking & $\begin{array}{c}\text { Fuzzy extension of } \\
\text { MAIRCA [19] }\end{array}$ & FTOPSIS & Proposed approach \\
\hline $\begin{array}{l}1^{\text {st }} \text { critical } \\
\text { FM }\end{array}$ & $\begin{array}{l}\text { Crack on raceways: } 35 \\
\text { times. } \\
\text { Fracture of shaft: } 7 \text { times } \\
\text { Others: } 2 \text { times }\end{array}$ & $\begin{array}{l}\text { Crack on raceways: } 33 \\
\text { times. } \\
\text { Fracture of shaft: } 8 \text { times } \\
\text { Others: } 2 \text { times }\end{array}$ & $\begin{array}{l}\text { Crack on raceways: } 35 \\
\text { times. } \\
\text { Fracture of shaft: } 7 \text { times } \\
\text { Others: } 3 \text { times }\end{array}$ \\
\hline $\begin{array}{l}2^{\text {nd }} \text { critical } \\
\text { FM }\end{array}$ & $\begin{array}{l}\text { Fracture of shafts: } 28 \\
\text { times, } \\
\text { Crack on raceways: } 5 \\
\text { times }\end{array}$ & $\begin{array}{l}\text { Fracture of shafts: } 25 \\
\text { times, } \\
\text { Crack on raceways: } 6 \\
\text { times }\end{array}$ & $\begin{array}{l}\text { Fracture of shafts: } 28 \\
\text { times, } \\
\text { Crack on raceways: } 5 \\
\text { times }\end{array}$ \\
\hline $\begin{array}{l}3^{\text {rd }} \text { critical } \\
\text { FM }\end{array}$ & $\begin{array}{l}\text { Cage defect: } 24 \text { times } \\
\text { Crack on rollers: } 11 \\
\text { times, } \\
\text { Others: } 9 \text { times }\end{array}$ & $\begin{array}{l}\text { Cage defect: } 22 \text { times } \\
\text { Crack on rollers: } 11 \text { times } \\
\text { Others: } 11 \text { times }\end{array}$ & $\begin{array}{l}\text { Crack on rollers: } 26 \\
\text { times } \\
\text { Cage defect: } 7 \text { times } \\
\text { Others: } 11 \text { times }\end{array}$ \\
\hline $\begin{array}{l}4^{\text {th }} \text { critical } \\
\text { FM }\end{array}$ & $\begin{array}{l}\text { Crack on rollers: } 21 \text { times } \\
\text { Cage defect: } 9 \text { times, } \\
\text { Others: } 14 \text { times }\end{array}$ & $\begin{array}{l}\text { Crack on rollers: } 20 \text { times } \\
\text { Cage defect: } 11 \text { times, } \\
\text { Others: } 13 \text { times }\end{array}$ & $\begin{array}{l}\text { Cage defect: } 25 \text { times, } \\
\text { Crack on rollers: } 6 \text { times, } \\
\text { Others: } 13 \text { times }\end{array}$ \\
\hline
\end{tabular}

3 From the above discussion, it is concluded that as the crack on bearing raceways (FM8) retains its

4 position for $80 \%$ of the scenarios, it can be considered as the most critical failure mode. Moreover, it is

5 observed that for most of the RFs, this FM8 failure mode is dominant above the fracture of a shaft

6 (FM12). For $64 \%$ of scenarios, the fracture of a shaft (FM12) maintains its second position and can be

7 considered as the second most critical failure mode. Furthermore, even considering up to $60 \%$ variation

8 in criteria weights, any drastic changes in these ranking results are not observed and the results also

9 show significant correlation $(\approx 90 \%)$ with the results obtained by the IT2FS-DEMATEL and

10 FMAIRCA approach. This high correlation signifies that the obtained ranking of failure modes using the new proposed methodology are confirmed and credible.

\section{Conclusions}

In an environment of sustainable manufacturing, it is required that all the processes associated with it become sustainable. Keeping these concerns in mind, in this study we have proposed an extended FMEA approach by considering how a failure mode of a machine can impact on the environmental, societal and economical aspects, necessitating their severity assessment integration within FMEA in order to reflect their benefits on sustainable manufacturing. With the increasing number of indices 
available for describing the severity, it becomes difficult for organizations to manage their exact values. In such circumstances, subjectively assessed experts' opinions are often utilized, but they themselves bear a vagueness that can lead to erroneous selection of critical failure mode(s). To overcome such eventualities, this study has proposed a hybrid MCGDM approach by combining IT2F-DEMATEL and modified FMAIRCA methods. The approach utilizing IT2F-DEMATEL has not only been used to calculate the causal dependencies but also the local priorities among the risk factors. Later, modified FMAIRCA has been utilized to rank the failure modes. Further, to validate the effectiveness of our approach, a case-study of a large and complex process plant gearbox was investigated. The reasons for considering this gearbox for comparing and validating our approach is its criticality in terms of giving the final shape and size of the red-hot cast blooms in the steel process plant. Any failure may cause damage to the finished goods and might jeopardize the safety of the operators. If so, organizations are compelled to reprocess it, which is not at all desirable due to the consequent generation of hazardous waste that may adversely affect not only the environment but also have economical and societal concerns.

Future extension of this research work includes a detailed study on identifying other risk factors of failure modes and an integrated strategy coupled with the practice of sustainable manufacturing. Researchers may extend this framework by examining the effectiveness of other newly developed weight calculations methods, such as SWARA, factor relationship (FARE) etc. Whereas, the application potential of other ranking methods, such as CODAS, EDAS can be examined in FMEA. Last but not least, for more credible decision making, this framework can be extended to include recently advanced theories, such as neutrosophic sets, 2-tuple linguistic fuzzy sets, Z-numbers, etc.

\section{Acknowledgement}

The authors would like to thank the Ministry of Human Resources and Development, India for providing financial assistance to carry out this work and the CIPRS scholarship provided through Curtin University. They would also like to thank Indian Institute of Technology Kharagpur, India and Curtin University, Western Australia for making a collaborative program for carrying out the research work.

\section{References}

[1] H. Gargama and S. K. Chaturvedi, "Criticality assessment models for failure mode effects and criticality analysis using fuzzy logic," IEEE Transactions on Reliability, vol. 60, no. 1, pp. 102110, 2011.

[2] J. B. Bowles and C. E. Peláez, "Fuzzy logic prioritization of failures in a system failure mode, effects and criticality analysis," Reliability Engineering \& System Safety, vol. 50, no. 2, pp. 203213, 1995.

[3] H.-C. Liu, "FMEA using uncertainty theories and MCDM methods," in FMEA using uncertainty theories and MCDM methods, Springer, 2016, pp. 13-27.

[4] H.-C. Liu, J.-X. You, X.-F. Ding, and Q. Su, "Improving risk evaluation in FMEA with a hybrid multiple criteria decision making method," International Journal of Quality \& Reliability Management, vol. 32, no. 7, pp. 763-782, 2015. 
[5] S. Carpitella, A. Certa, J. Izquierdo, and C. M. La Fata, "A combined multi-criteria approach to support FMECA analyses: A real-world case," Reliability Engineering \& System Safety, vol. 169, pp. 394-402, 2018.

[6] W. Song, X. Ming, Z. Wu, and B. Zhu, "Failure modes and effects analysis using integrated weight-based fuzzy TOPSIS," International Journal of Computer Integrated Manufacturing, vol. 26, no. 12, pp. 1172-1186, 2013.

[7] J. Huang, Z. S. Li, and H.-C. Liu, "New approach for failure mode and effect analysis using linguistic distribution assessments and TODIM method," Reliability Engineering \& System Safety, vol. 167, pp. 302-309, 2017.

[8] Z. Tian, J. Wang, and H. Zhang, "An integrated approach for failure mode and effects analysis based on fuzzy best-worst, relative entropy, and VIKOR methods," Applied Soft Computing, vol. 72, pp. 636-646, 2018.

[9] H.-W. Lo, J. J. Liou, C.-N. Huang, and Y.-C. Chuang, "A novel failure mode and effect analysis model for machine tool risk analysis," Reliability Engineering \& System Safety, vol. 183, pp. 173$183,2019$.

[10] K. Lijesh, S. Muzakkir, and H. Hirani, "Failure mode and effect analysis of passive magnetic bearing," Engineering Failure Analysis, vol. 62, pp. 1-20, 2016.

[11] E. Vijay Kumar and S. Chaturvedi, "Prioritization of maintenance tasks on industrial equipment for reliability: a fuzzy approach," International Journal of Quality \& Reliability Management, vol. 28, no. 1, pp. 109-126, 2011.

[12] W. Faulkner and F. Badurdeen, "Sustainable Value Stream Mapping (Sus-VSM): methodology to visualize and assess manufacturing sustainability performance," Journal of cleaner production, vol. 85, pp. 8-18, 2014.

[13] S. Boral, S. K. Chaturvedi, V. Naikan, and I. M. Howard, "A Hybrid AI-Based Conceptual Decision-Making Model for Sustainable Maintenance Strategy Selection," in Advanced MultiCriteria Decision Making for Addressing Complex Sustainability Issues, IGI Global, 2019, pp. 63-93.

[14] B. S. Silvestre and D. M. Ţîrcă, "Innovations for sustainable development: Moving toward a sustainable future," Journal of Cleaner Production, vol. 208, pp. 325-332, 2019.

[15] L. A. Zadeh, "Fuzzy sets," Information and control, vol. 8, no. 3, pp. 338-353, 1965.

[16] H.-C. Liu, X.-Q. Chen, C.-Y. Duan, and Y.-M. Wang, "Failure mode and effect analysis using multi-criteria decision making methods: A systematic literature review," Computers \& Industrial Engineering, 2019.

[17] L. A. Zadeh, "The concept of a linguistic variable and its application to approximate reasoningI," Information sciences, vol. 8, no. 3, pp. 199-249, 1975.

[18] A. Baykasoğlu and İ. Gölcük, "Development of an interval type-2 fuzzy sets based hierarchical MADM model by combining DEMATEL and TOPSIS," Expert Systems with Applications, vol. 70, pp. 37-51, 2017.

[19] D. Pamučar, L. Vasin, and L. Lukovac, "Selection of railway level crossings for investing in security equipment using hybrid DEMA ${ }^{\mathrm{TEL}}$-MARICA model," in XVI International Scientificexpert Conference on Railway, Railcon, 2014, pp. 89-92.

[20] K. Chatterjee, D. Pamucar, and E. K. Zavadskas, "Evaluating the performance of suppliers based on using the R'AMA ${ }^{\mathrm{TEL}}$-MAIRCA method for green supply chain implementation in electronics industry," Journal of cleaner production, vol. 184, pp. 101-129, 2018.

[21] D. Pamučar, V. Lukovac, D. Božanić, and N. Komazec, "Multi-criteria FUCOM-MAIRCA model for the evaluation of level crossings: case study in the Republic of Serbia," Operational Research in Engineering Sciences: Theory and Applications, vol. 1, no. 1, pp. 108-129, 2018.

[22] I. Badi and M. Ballem, "Supplier selection using the rough BWM-MAIRCA model: A case study in pharmaceutical supplying in Libya," Decision Making: Applications in Management and Engineering, vol. 1, no. 2, pp. 16-33, 2018.

[23] L. Gigović, D. Pamučar, Z. Bajić, and M. Milićević, "The combination of expert judgment and GIS-MAIRCA analysis for the selection of sites for ammunition depots," Sustainability, vol. 8, no. 4, p. 372, 2016. 
[24] U. Asan and A. Soyer, "Failure mode and effects analysis under uncertainty: a literature review and tutorial," in Intelligent Decision Making in Quality Management, Springer, 2016, pp. 265325.

[25] H.-C. Liu, L. Liu, and N. Liu, "Risk evaluation approaches in failure mode and effects analysis: A literature review," Expert systems with applications, vol. 40, no. 2, pp. 828-838, 2013.

[26] B. J. Garrick, "The approach to risk analysis in three industries: nuclear power, space systems, and chemical process," Reliability Engineering \& System Safety, vol. 23, no. 3, pp. 195-205, 1988.

[27] M. Braglia, "MAFMA: multi-attribute failure mode analysis," International Journal of Quality \& Reliability Management, vol. 17, no. 9, pp. 1017-1033, 2000.

[28] S. J. Rhee and K. Ishii, "Using cost based FMEA to enhance reliability and serviceability," Advanced Engineering Informatics, vol. 17, no. 3-4, pp. 179-188, 2003.

[29] M. Braglia, G. Fantoni, and M. Frosolini, "The house of reliability," International Journal of Quality \& Reliability Management, vol. 24, no. 4, pp. 420-440, 2007.

[30] A. von Ahsen, "Cost-oriented failure mode and effects analysis," International Journal of Quality \& Reliability Management, vol. 25, no. 5, pp. 466-476, 2008.

[31] G. Carmignani, "An integrated structural framework to cost-based FMECA: The priority-cost FMECA," Reliability Engineering \& System Safety, vol. 94, no. 4, pp. 861-871, 2009.

[32] F. Zammori and R. Gabbrielli, "ANP/RPN: A multi criteria evaluation of the risk priority number," Quality and Reliability Engineering International, vol. 28, no. 1, pp. 85-104, 2012.

[33] A. Silvestri, F. De Felice, and A. Petrillo, "Multi-criteria risk analysis to improve safety in manufacturing systems," International Journal of Production Research, vol. 50, no. 17, pp. 48064821, 2012.

[34] D. Das Adhikary, G. Kumar Bose, D. Bose, and S. Mitra, "Multi criteria FMECA for coal-fired thermal power plants using COPRAS-G," International Journal of Quality \& Reliability Management, vol. 31, no. 5, pp. 601-614, 2014.

[35] S. Yousefi, A. Alizadeh, J. Hayati, and M. Baghery, "HSE risk prioritization using robust DEAFMEA approach with undesirable outputs: a study of automotive parts industry in Iran," Safety science, vol. 102, pp. 144-158, 2018.

[36] Y. Du, H. Mo, X. Deng, R. Sadiq, and Y. Deng, "A new method in failure mode and effects analysis based on evidential reasoning," International Journal of System Assurance Engineering and Management, vol. 5, no. 1, pp. 1-10, 2014.

[37] K.-H. Chang, "A novel general risk assessment method using the soft TOPSIS approach," Journal of Industrial and Production Engineering, vol. 32, no. 6, pp. 408-421, 2015.

[38] H.-C. Liu, J.-X. You, M.-M. Shan, and L.-N. Shao, "Failure mode and effects analysis using intuitionistic fuzzy hybrid TOPSIS approach," Soft Computing, vol. 19, no. 4, pp. 1085-1098, 2015.

[39] T. Bian, H. Zheng, L. Yin, and Y. Deng, "Failure mode and effects analysis based on D numbers and TOPSIS," Quality and Reliability Engineering International, vol. 34, no. 4, pp. 501-515, 2018.

[40] M. Mangeli, A. Shahraki, and F. H. Saljooghi, "Improvement of risk assessment in the FMEA using nonlinear model, revised fuzzy TOPSIS, and support vector machine," International Journal of Industrial Ergonomics, vol. 69, pp. 209-216, 2019.

[41] H.-C. Liu, L.-E. Wang, Z. Li, and Y.-P. Hu, "Improving Risk Evaluation in FMEA With Cloud Model and Hierarchical TOPSIS Method," IEEE Transactions on Fuzzy Systems, vol. 27, no. 1, pp. 84-95, 2019.

[42] H.-C. Liu, J.-X. You, X.-Y. You, and M.-M. Shan, "A novel approach for failure mode and effects analysis using combination weighting and fuzzy VIKOR method," Applied Soft Computing, vol. 28, pp. 579-588, 2015.

[43] Z. Wang, J.-M. Gao, R.-X. Wang, K. Chen, Z.-Y. Gao, and W. Zheng, "Failure mode and effects analysis by using the house of reliability-based rough VIKOR approach," IEEE Transactions on Reliability, vol. 67, no. 1, pp. 230-248, 2018.

[44] H.-C. Liu, J.-X. You, S. Chen, and Y.-Z. Chen, "An integrated failure mode and effect analysis approach for accurate risk assessment under uncertainty," Iie Transactions, vol. 48, no. 11, pp. 1027-1042, 2016. 
[45] A. Certa, M. Enea, G. M. Galante, and C. M. La Fata, "ELECTRE TRI-based approach to the failure modes classification on the basis of risk parameters: An alternative to the risk priority number," Computers \& Industrial Engineering, vol. 108, pp. 100-110, 2017.

[46] H.-C. Liu, J.-X. You, P. Li, and Q. Su, "Failure mode and effect analysis under uncertainty: An integrated multiple criteria decision making approach," IEEE Transactions on Reliability, vol. 65, no. 3, pp. 1380-1392, 2016.

[47] H.-C. Liu, Z. Li, W. Song, and Q. Su, "Failure mode and effect analysis using cloud model theory and PROMETHEE method," IEEE Transactions on Reliability, vol. 66, no. 4, pp. 1058-1072, 2017.

[48] L.-E. Wang, H.-C. Liu, and M.-Y. Quan, "Evaluating the risk of failure modes with a hybrid MCDM model under interval-valued intuitionistic fuzzy environments," Computers \& Industrial Engineering, vol. 102, pp. 175-185, 2016.

[49] H.-C. Liu, X.-J. Fan, P. Li, and Y.-Z. Chen, "Evaluating the risk of failure modes with extended MULTIMOORA method under fuzzy environment," Engineering Applications of Artificial Intelligence, vol. 34, pp. 168-177, 2014.

[50] H. Zhao, J.-X. You, and H.-C. Liu, "Failure mode and effect analysis using MULTIMOORA method with continuous weighted entropy under interval-valued intuitionistic fuzzy environment," Soft Computing, vol. 21, no. 18, pp. 5355-5367, 2017.

[51] R. Fattahi and M. Khalilzadeh, "Risk evaluation using a novel hybrid method based on FMEA, extended MULTIMOORA, and AHP methods under fuzzy environment," Safety science, vol. 102, pp. 290-300, 2018.

[52] H.-C. Liu, J.-X. You, and C.-Y. Duan, "An integrated approach for failure mode and effect analysis under interval-valued intuitionistic fuzzy environment," International Journal of Production Economics, vol. 207, pp. 163-172, 2019.

[53] A. Gugaliya, S. Boral, and V. Naikan, "A hybrid decision making framework for modified failure mode effects and criticality analysis: A case study on process plant induction motors," International Journal of Quality \& Reliability Management, 2019.

[54] A. D. Torshizi, M. H. F. Zarandi, and H. Zakeri, "On type-reduction of type-2 fuzzy sets: A review," Applied Soft Computing, vol. 27, pp. 614-627, 2015.

[55] S. Boral, S. K. Chaturvedi, and V. Naikan, "A case-based reasoning system for fault detection and isolation: a case study on complex gearboxes," Journal of Quality in Maintenance Engineering, 2019.

[56] S. Opricovic, "Fuzzy VIKOR with an application to water resources planning," Expert Systems with Applications, vol. 38, no. 10, pp. 12983-12990, 2011.

[57] D. Pamučar, M. Mihajlović, R. Obradović, and P. Atanasković, "Novel approach to group multicriteria decision making based on interval rough numbers: Hybrid DEMATEL-ANP-MAIRCA model," Expert Systems with Applications, vol. 88, pp. 58-80, 2017. 
Appendix A.1. Dependency degree obtained from DMs for main attributes - severity, occurrence and detection

\begin{tabular}{||c|c|c|c|c|c|c|c||c|c|c|c||}
\hline \hline DM1 & S & O & D & DM2 & S & O & D & DM3 & S & O & D \\
\hline S & & M & VH & S & & VL & VVH & $\mathbf{S}$ & & L & VH \\
\hline $\mathbf{O}$ & L & & & $\mathbf{O}$ & M & & & $\mathbf{O}$ & VL & & \\
$\mathbf{D}$ & H & & & D & VH & & & $\mathbf{D}$ & H & & \\
\hline
\end{tabular}

Appendix A.2. Dependency degree obtained from DMs for economic, social and environmental factors

\begin{tabular}{||cccc||c|c|c|c||c|c|c|c||}
\hline \hline DM1 & Ec & So & En & DM2 & Ec & So & En & DM3 & Ec & So & En \\
Ec & & H & M & Ec & & M & H & Ec & & H & M \\
So & M & & VH & So & VH & & & So & H & & \\
En & H & M & & En & M & H & & En & H & M & \\
\hline
\end{tabular}

Appendix A.3. Dependency degree obtained from DMs for chances of accident, overtime due to failure and effects on worker's mind-set

\begin{tabular}{||c|c|c|c|c|c|c|c|c||c|c|c|c||}
\hline \hline DM1 & CA & ODF & EWM & DM2 & CA & ODF & EWM & DM3 & CA & ODF & EWM \\
CA & & & VH & CA & & & H & CA & & & M \\
ODF & VL & & H & ODF & H & & M & ODF & L & & M \\
\hline EWM & M & H & & EWM & H & M & & EWM & VL & L & \\
\hline
\end{tabular}

Appendix A.4. Dependency degree obtained from DMs for cost of unreliability, cost of quality loss and misc. cost

\begin{tabular}{||c|c|c|c||c|c|c|c|c|c|c|c||}
\hline \hline DM1 & CoUR & CoQL & MsCo & DM2 & CoUR & CoQL & MsCo & DM3 & CoUR & CoQL & MsCo \\
CoUR & & VH & M & CoUr & & H & H & CoUr & & M & VH \\
CoQL & L & & & CoQ & H & & & CoQ & M & & \\
MsCo & H & & & MsCo & VH & & & MsCo & H & & \\
\hline
\end{tabular}

Appendix A.5. Dependency degree obtained from DMs for generation of waste material, excess energy consumption and misc. environmental factors

\begin{tabular}{||c|c|c|c|c|c|c|c|c||c|c|c||}
\hline \hline DM1 & GWM & EEC & MsEF & DM2 & GWM & EEC & MsEF & DM3 & GWM & EEC & MsEF \\
GWM & & VH & M & GWM & & H & H & GWM & & VH & M \\
EEC & M & & L & EEC & L & & M & EEC & H & & H \\
MsEF & M & & & MsEF & H & & & MsEF & L & & \\
\hline
\end{tabular}


Appendix B.1. Initial Direct Relation Matrix for S-O-D

\begin{tabular}{|c|c|c|c|}
\hline & Severity & Occurrence & Detection \\
\hline Severity & $((0,0,0,0 ; 1,1),(0,0,0,0 ; 0.9,0.9))$ & $\left(\begin{array}{c}(0.217,0.350,0.350,0.500 ; 1,1), \\
(0.267,0.350,0.350,0.450 ; 0.9,0.9)\end{array}\right)$ & $\left(\begin{array}{c}(0.700,0.833,0.833,0.933 ; 1,1), \\
(0.750,0.833,0.833,0.883 ; 0.9,0.9)\end{array}\right)$ \\
\hline Occurrence & $\left(\begin{array}{c}(0.217,0.350,0.650,0.500 ; 1,1), \\
(0.267,0.350,0.350,0.450 ; 0.9,0.9)\end{array}\right)$ & $((0,0,0,0 ; 1,1),(0,0,0,0 ; 0.9,0.9))$ & $((0,0,0,0 ; 1,1),(0,0,0,0 ; 0.9,0.9))$ \\
\hline Detection & $\left.\begin{array}{c}(0.550,0.700,0.700,0.833 ; 1,1), \\
(0.600,0.700,0.700,0.783 ; 0.9,0.9)\end{array}\right)$ & $((0,0,0,0 ; 1,1),(0,0,0,0 ; 0.9,0.9))$ & $((0,0,0,0 ; 1,1),(0,0,0,0 ; 0.9,0.9))$ \\
\hline
\end{tabular}

Appendix B.2. Normalized initial direct-relation matrix for S-O-D

\begin{tabular}{|c|c|c|c|}
\hline & Severity & Occurrence & Detection \\
\hline Severity & $((0,0,0,0 ; 1,1),(0,0,0,0 ; 0.9,0.9))$ & $\left(\begin{array}{c}(0.1914,0.3720,0.3720,0.6981 ; 1,1), \\
(0.249,0.372,0.372,0.556 ; 0.9,0.9)\end{array}\right)$ & $\left(\begin{array}{c}(0.488,0.581,0.581,0.651 ; 1,1), \\
(0.523,0.581,0.581,0.616 ; 0.9,0.9)\end{array}\right)$ \\
\hline Occurrence & $\left.\begin{array}{c}(0.151,0.244,0.0 .244,0.349 ; 1,1), \\
(0.186,0.244,0.244,0.314 ; 0.9,0.9)\end{array}\right)$ & $((0,0,0,0 ; 1,1),(0,0,0,0 ; 0.9,0.9))$ & $((0,0,0,0 ; 1,1),(0,0,0,0 ; 0.9,0.9))$ \\
\hline Detection & $\left.\begin{array}{c}(0.384,0.488,0.488,0.581 ; 1,1), \\
(0.419,0.488,0.488,0.547 ; 0.9,0.9)\end{array}\right)$ & $((0,0,0,0 ; 1,1),(0,0,0,0 ; 0.9,0.9))$ & $((0,0,0,0 ; 1,1),(0,0,0,0 ; 0.9,0.9))$ \\
\hline
\end{tabular}

Appendix B.3. Total relation matrix for S-O-D

\begin{tabular}{|c|c|c|c|}
\hline & Severity & Occurrence & Detection \\
\hline Severity & $\left(\begin{array}{c}(0.2662,0.5234,0.5234,1.0011 ; 1,1), \\
(0.340,0.523,0.523,0.771 ; 0.9,0.9)\end{array}\right)$ & $\left(\begin{array}{c}(0.151,0.244,0.244,0.349 ; 1,1), \\
(0.186,0.244,0.244,0.314 ; 0.9,0.9)\end{array}\right)$ & $\left(\begin{array}{c}(0.6184,0.8857,0.8857,1.3030 ; 1,1), \\
(0.701,0.886,0.886,1.091 ; 0.9,0.9)\end{array}\right)$ \\
\hline Occurrence & $\left(\begin{array}{c}(0.1914,0.3720,0.3720,0.6981 ; 1,1), \\
(0.249,0.372,0.372,0.556 ; 0.9,0.9)\end{array}\right)$ & $\left(\begin{array}{c}(0.0289,0.0908,0.0908,0.2435 ; 1,1), \\
(0.046,0.091,0.091,0.175 ; 0.9,0.9)\end{array}\right)$ & $\left(\begin{array}{c}(0.0935,0.2163,0.2163,0.4545 ; 1,1), \\
(0.130,0.216,0.216,0.343 ; 0.9,0.9)\end{array}\right)$ \\
\hline Detection & $\left(\begin{array}{c}(0.4859,0.7440,0.7440,1.1634 ; 1,1), \\
(0.561,0.744,0.744,0.968 ; 0.9,0.9)\end{array}\right)$ & $\left(\begin{array}{c}(0.0734,0.1817,0.1817,0.4058 ; 1,1), \\
(0.104,0.182,0.182,0.304 ; 0.9,0.9)\end{array}\right)$ & $\left(\begin{array}{c}(0.2373,0.4325,0.4325,0.7576 ; 1,1), \\
(0.293,0.433,0.433,0.597 ; 0.9,0.9)\end{array}\right)$ \\
\hline
\end{tabular}


Appendix C. Linguistic decision matrix

\begin{tabular}{|c|c|c|c|c|c|c|c|c|c|c|c|c|}
\hline $\begin{array}{l}\text { Failure } \\
\text { Modes }\end{array}$ & & C111 & C112 & C113 & C121 & C122 & C123 & C131 & C132 & C133 & C2 & C3 \\
\hline \multirow{3}{*}{$\begin{array}{c}\text { Wear of } \\
\text { Teeth (FM1) }\end{array}$} & DM1 & MG & MP & $P$ & $P$ & $\mathrm{~F}$ & G & $\mathrm{F}$ & $F$ & $\mathrm{~F}$ & $P$ & $\mathrm{MG}$ \\
\hline & DM2 & $\mathrm{G}$ & $P$ & $P$ & VP & MP & MG & $\mathrm{F}$ & MP & $\mathrm{P}$ & MP & $\mathrm{F}$ \\
\hline & DM3 & MG & MP & VP & $\mathrm{P}$ & MP & G & $\mathrm{F}$ & $\mathrm{P}$ & $\mathrm{P}$ & $\mathrm{F}$ & $\mathrm{MG}$ \\
\hline \multirow{3}{*}{$\begin{array}{c}\text { Broken } \\
\text { Teeth (FM2) }\end{array}$} & DM1 & G & $\mathrm{P}$ & $P$ & $\mathrm{P}$ & G & $\mathrm{G}$ & $\mathrm{F}$ & MP & $\mathrm{P}$ & $F$ & $\mathrm{VG}$ \\
\hline & DM2 & $\mathrm{VG}$ & MP & MP & $\mathrm{P}$ & $\mathrm{VG}$ & MG & MG & $F$ & $\mathrm{P}$ & MP & $\mathrm{G}$ \\
\hline & DM3 & G & $\mathrm{P}$ & $\mathrm{P}$ & MP & G & MG & $\mathrm{F}$ & $\mathrm{F}$ & MP & MP & $\mathrm{G}$ \\
\hline \multirow{3}{*}{$\begin{array}{c}\text { Pitting of } \\
\text { Gear (FM3) }\end{array}$} & DM1 & $\mathrm{F}$ & VP & $F$ & $\mathrm{P}$ & $\mathrm{MG}$ & G & MP & MP & $\mathrm{P}$ & $\mathrm{F}$ & $\mathrm{G}$ \\
\hline & DM2 & MP & $\mathrm{P}$ & MP & $\mathrm{P}$ & $\mathrm{MG}$ & G & $\mathrm{F}$ & $\mathrm{P}$ & $\mathrm{P}$ & $\mathrm{F}$ & $\mathrm{MG}$ \\
\hline & DM3 & $\mathrm{MG}$ & MP & $\mathrm{P}$ & MP & $\mathrm{G}$ & $\mathrm{G}$ & $\mathrm{P}$ & MP & MP & MP & $\mathrm{G}$ \\
\hline \multirow{3}{*}{$\begin{array}{l}\text { Axial Shift } \\
\text { of Gear } \\
\text { (FM4) }\end{array}$} & DM1 & VG & $F$ & $\mathrm{P}$ & $\mathrm{F}$ & MP & MG & $\mathrm{P}$ & G & $\mathrm{P}$ & $\mathrm{P}$ & MP \\
\hline & DM2 & G & $\mathrm{MG}$ & $\mathrm{F}$ & MP & MP & $F$ & VP & G & $F$ & MP & $\mathrm{F}$ \\
\hline & DM3 & $\mathrm{VG}$ & $F$ & MP & $F$ & $\mathrm{P}$ & $\mathrm{F}$ & $\mathrm{P}$ & $\mathrm{F}$ & $\mathrm{P}$ & $F$ & MP \\
\hline \multirow{3}{*}{$\begin{array}{l}\text { Scoring of } \\
\text { gears (FM5) }\end{array}$} & DM1 & $\mathrm{P}$ & $\mathrm{P}$ & $\mathrm{P}$ & $\mathrm{P}$ & $\mathrm{G}$ & $\mathrm{MG}$ & $\mathrm{P}$ & MP & $\mathrm{P}$ & $\mathrm{F}$ & $\mathrm{F}$ \\
\hline & DM2 & MP & $\mathrm{P}$ & $\mathrm{P}$ & $\mathrm{P}$ & G & G & $\mathrm{P}$ & $\mathrm{P}$ & MP & MP & $\mathrm{F}$ \\
\hline & DM3 & $\mathrm{P}$ & MP & MP & MP & MG & $\mathrm{G}$ & $\mathrm{F}$ & $\mathrm{P}$ & MP & MP & $\mathrm{MG}$ \\
\hline \multirow{3}{*}{$\begin{array}{c}\text { Brinelling } \\
\text { (FM6) }\end{array}$} & DM1 & $\mathrm{MG}$ & MP & $\mathrm{P}$ & $\mathrm{P}$ & $\mathrm{F}$ & $\mathrm{G}$ & $\mathrm{F}$ & MP & $\mathrm{P}$ & $\mathrm{F}$ & $\mathrm{MP}$ \\
\hline & DM2 & $\mathrm{F}$ & $\mathrm{F}$ & $\mathrm{P}$ & $\mathrm{P}$ & $\mathrm{MG}$ & MG & $\mathrm{F}$ & $\mathrm{P}$ & $\mathrm{F}$ & MG & MP \\
\hline & DM3 & $\mathrm{F}$ & MP & $\mathrm{P}$ & MP & $\mathrm{MG}$ & $F$ & $\mathrm{P}$ & $\mathrm{P}$ & MP & MG & $\mathrm{F}$ \\
\hline \multirow{3}{*}{$\begin{array}{l}\text { Cage defect } \\
\text { (FM7) }\end{array}$} & DM1 & $\bar{G}$ & $\mathrm{~F}$ & $\bar{G}$ & $F$ & $\mathrm{P}$ & $\mathrm{P}$ & $\mathrm{VG}$ & $\bar{G}$ & $\mathrm{~F}$ & $\mathrm{P}$ & $\mathrm{VG}$ \\
\hline & DM2 & $\mathrm{VG}$ & $\mathrm{MG}$ & G & $\mathrm{P}$ & $F$ & $\mathrm{P}$ & $\mathrm{VG}$ & $F$ & $\mathrm{~F}$ & MP & $\mathrm{VG}$ \\
\hline & DM3 & G & $\mathrm{F}$ & $\mathrm{VG}$ & MP & $\mathrm{F}$ & MP & G & $\mathrm{MG}$ & $\mathrm{P}$ & $\mathrm{P}$ & $\mathrm{G}$ \\
\hline \multirow{3}{*}{$\begin{array}{c}\text { Crack on } \\
\text { raceways } \\
(\mathrm{FM} 8)\end{array}$} & DM1 & $\mathrm{VG}$ & $\mathrm{MG}$ & G & $\mathrm{P}$ & $\mathrm{P}$ & MP & MP & $\mathrm{G}$ & MP & G & $\mathrm{VG}$ \\
\hline & DM2 & $\mathrm{VG}$ & $\mathrm{F}$ & $\mathrm{F}$ & $\mathrm{P}$ & MP & $\mathrm{F}$ & MP & MG & $\mathrm{P}$ & $\mathrm{G}$ & VG \\
\hline & DM3 & G & $F$ & G & $\mathrm{MP}$ & $\mathrm{P}$ & MP & $\mathrm{P}$ & G & $\mathrm{P}$ & VG & $\mathrm{VG}$ \\
\hline \multirow{3}{*}{$\begin{array}{c}\text { Crack of } \\
\text { rollers } \\
\text { (FM9) }\end{array}$} & DM1 & $\mathrm{G}$ & $\mathrm{MG}$ & $\mathrm{F}$ & $\mathrm{P}$ & $\mathrm{P}$ & MP & $\mathrm{VG}$ & $\mathrm{G}$ & $\mathrm{F}$ & $\mathrm{F}$ & $\mathrm{G}$ \\
\hline & DM2 & $\mathrm{VG}$ & $\mathrm{G}$ & $\mathrm{F}$ & $\mathrm{P}$ & $\mathrm{P}$ & $\mathrm{P}$ & $\mathrm{VG}$ & $\mathrm{G}$ & $\mathrm{P}$ & MP & $\mathrm{MG}$ \\
\hline & DM3 & $\mathrm{G}$ & $\mathrm{F}$ & $\mathrm{G}$ & MP & $\mathrm{F}$ & $\mathrm{P}$ & $\mathrm{G}$ & $\mathrm{G}$ & $\mathrm{F}$ & $\mathrm{F}$ & $\mathrm{VG}$ \\
\hline \multirow{3}{*}{$\begin{array}{l}\text { Bent shaft } \\
\text { (FM10) }\end{array}$} & DM1 & $\mathrm{G}$ & $\mathrm{G}$ & $\mathrm{F}$ & MG & $\mathrm{P}$ & $\mathrm{P}$ & $\mathrm{F}$ & $\bar{G}$ & $\mathrm{~F}$ & MP & $\mathrm{F}$ \\
\hline & DM2 & MG & $\mathrm{MG}$ & MP & MG & $\mathrm{P}$ & $\mathrm{P}$ & $\mathrm{F}$ & $\mathrm{VG}$ & $\mathrm{P}$ & $\mathrm{F}$ & $\mathrm{F}$ \\
\hline & DM3 & $\mathrm{G}$ & $\mathrm{G}$ & MP & $\mathrm{F}$ & MP & VP & $\mathrm{P}$ & $\mathrm{G}$ & $\mathrm{F}$ & MP & $\mathrm{MG}$ \\
\hline \multirow{3}{*}{$\begin{array}{c}\text { Crack of } \\
\text { shaft } \\
\text { (FM11) }\end{array}$} & DM1 & MG & $\mathrm{G}$ & $\mathrm{G}$ & $\mathrm{F}$ & MP & $\mathrm{F}$ & $\mathrm{F}$ & $\mathrm{G}$ & MP & MP & $\mathrm{F}$ \\
\hline & DM2 & $\mathrm{G}$ & $\mathrm{G}$ & $\mathrm{VG}$ & MG & $\mathrm{P}$ & $\mathrm{F}$ & MP & $\mathrm{G}$ & $F$ & $\mathrm{P}$ & $\mathrm{F}$ \\
\hline & DM3 & $\mathrm{VG}$ & $F$ & G & $F$ & MP & $F$ & $\mathrm{~F}$ & $\mathrm{G}$ & $F$ & $\mathrm{P}$ & $\mathrm{MG}$ \\
\hline \multirow{3}{*}{$\begin{array}{c}\text { Fracture of } \\
\text { shaft } \\
\text { (FM12) }\end{array}$} & DM1 & $\mathrm{VG}$ & $\mathrm{VG}$ & $\mathrm{P}$ & $\mathrm{VG}$ & $\mathrm{P}$ & $\mathrm{F}$ & $\mathrm{VG}$ & $\mathrm{VG}$ & $\mathrm{F}$ & $\mathrm{P}$ & $\mathrm{VG}$ \\
\hline & DM2 & $\mathrm{VG}$ & $\mathrm{G}$ & $\mathrm{P}$ & $\mathrm{G}$ & $\mathrm{P}$ & $\mathrm{MG}$ & $\mathrm{G}$ & $\mathrm{G}$ & $\mathrm{G}$ & $\mathrm{VP}$ & $\mathrm{VG}$ \\
\hline & DM3 & $\mathrm{G}$ & $\mathrm{G}$ & MP & $\mathrm{VG}$ & MP & $\mathrm{F}$ & $\mathrm{G}$ & $\mathrm{VG}$ & $\mathrm{G}$ & $\mathrm{P}$ & $\mathrm{G}$ \\
\hline
\end{tabular}

